\title{
Research Progress in Chinese Herbal Medicines for Treatment of Sepsis: Pharmacological Action, Phytochemistry, and Pharmacokinetics
}

\author{
Chen Cheng *D and Xuan Yu
}

Citation: Cheng, C.; Yu, X. Research Progress in Chinese Herbal Medicines for Treatment of Sepsis:

Pharmacological Action,

Phytochemistry, and

Pharmacokinetics. Int. J. Mol. Sci. 2021, 22, 11078. https://doi.org/ 10.3390/ijms222011078

Academic Editor: Magdalena Ca

Received: 19 September 2021

Accepted: 13 October 2021

Published: 14 October 2021

Publisher's Note: MDPI stays neutral with regard to jurisdictional claims in published maps and institutional affiliations.

Copyright: (c) 2021 by the authors. Licensee MDPI, Basel, Switzerland. This article is an open access article distributed under the terms and conditions of the Creative Commons Attribution (CC BY) license (https:// creativecommons.org/licenses/by/ $4.0 /)$
State Key Laboratory of Drug Research, Shanghai Institute of Materia Medica, Chinese Academy of Sciences, 501 Haike Road, Zhangiiang Hi-Tech Park, Shanghai 201203, China; 201728012342061@simm.ac.cn

* Correspondence: chengchen@simm.ac.cn

\begin{abstract}
Sepsis is a life-threatening organ dysfunction caused by a dysregulated host response to infection; the pathophysiology of sepsis is complex. The incidence of sepsis is steadily increasing, with worldwide mortality ranging between $30 \%$ and $50 \%$. Current treatment approaches mainly rely on the timely and appropriate administration of antimicrobials and supportive therapies, but the search for pharmacotherapies modulating the host response has been unsuccessful. Chinese herbal medicines, i.e., Chinese patent medicines, Chinese herbal prescriptions, and single Chinese herbs, play an important role in the treatment of sepsis through multicomponent, multipathway, and multitargeting abilities and have been officially recommended for the management of COVID-19. Chinese herbal medicines have therapeutic actions promising for the treatment of sepsis; basic scientific research on these medicines is increasing. However, the material bases of most Chinese herbal medicines and their underlying mechanisms of action have not yet been fully elucidated. This review summarizes the current studies of Chinese herbal medicines used for the treatment of sepsis in terms of clinical efficacy and safety, pharmacological activity, phytochemistry, bioactive constituents, mechanisms of action, and pharmacokinetics, to provide an important foundation for clarifying the pathogenesis of sepsis and developing novel antisepsis drugs based on Chinese herbal medicines.
\end{abstract}

Keywords: antiseptic actions; Chinese herbal medicines; material basis; Qingwen Baidu decoction; Shengfu injection; Shengmai; sepsis; Xuanbai Chengqi decoction; XueBiJing injection

\section{Introduction}

Sepsis is life-threatening organ dysfunction caused by a dysregulated host response to infection [1]. A meta-analysis showed that the 10-year incidence (2005-2015) of sepsis and severe sepsis in developed countries was 437 and 270 per 100,000 population per year, respectively, while mortality was $17 \%$ and $26 \%$, respectively [2]. Severe sepsis was defined as a host's systemic inflammatory response syndrome (SIRS) to infection complicated by organ dysfunction. The terms SIRS and severe sepsis were deleted in February 2016, when the European Society of Intensive Care Medicine and the Society of Critical Care Medicine (SCCM) published new consensus definitions of sepsis and related clinical criteria (Sepsis-3) [1]. Sepsis has exceeded myocardial infarctions in terms of the mortality rate and has become a major cause of death in non-cardiac patients in intensive care units (ICUs). According to a domestic epidemiological investigation, the incidence of sepsis and the 90-day mortality rate among ICU patients in 44 Chinese hospitals were $20.6 \%$ and $35.5 \%$, respectively, while the mortality was as high as $50 \%$ or above for severe cases [3]. Coronavirus disease 2019 (COVID-19) created a global public health emergency since its original outbreak at the end of 2019 [4]. The ongoing COVID-19 pandemic has infected over 20,000,000 people around the world, claiming the lives of nearly 5 million people worldwide. Among the patients hospitalized with COVID-19, 26\% have been treated as critical cases, which could involve sepsis or even septic shock [5]. Septic shock is a 
subset of sepsis in which underlying circulatory and cellular-metabolic abnormalities are profound enough to substantially increase mortality, and operationally defined as requiring vasopressor therapy to maintain a mean arterial blood pressure of $>65 \mathrm{mmHg}$ and an increased plasma lactate level of $>2 \mathrm{mmol} / \mathrm{L}[1,6]$. The proposed criteria for sepsis and septic shock were summarized by Hotchkiss et al. and Gotts et al. [6,7].

Due to the high incidence and mortality of sepsis [3], its diagnosis and treatment have been the focuses of critical medicine, emergency medicine, and infectious diseases studies. Sepsis diagnoses (versions 1.0, 2.0, and 3.0), as well as various treatment plans, have been proposed by experts since 1992 [1,8,9]. Sepsis is commonly characterized by complex mechanisms that involve coagulation abnormalities, the uncontrolled release of inflammatory mediators, an excessive innate immune response, endothelial capillary leakage syndrome, organ dysfunction, etc. $[10,11]$. The current treatment approaches mainly rely on the timely and appropriate administration of antimicrobials, as well as supportive therapies [12]. Although the pathophysiology of sepsis is now much better understood, the search for pharmacotherapies for modulating the septic response has been unsuccessful, and the incidence and mortality of sepsis have not significantly decreased over the past two decades $[13,14]$.

To treat both the symptoms and internal causes of disease, traditional Chinese medicine (TCM) advocates a harmonious, balanced state of the body; it provides advantages in treating different stages of sepsis [15]. Chinese herbal medicines (CHMs) can inhibit platelet aggregation, regulate inflammation and the immune response, and improve microcirculation to thus prevent the progression of sepsis and improve the prognosis of sepsis patients. Such medicines include Chinese patent medicines, Chinese herbal prescriptions, and single Chinese herbs. In the early stage of sepsis, a combination of CHM with antibiotics could reduce the occurrence of drug-resistant bacteria, especially for patients with drug-resistant infections [15]. With the development of sepsis, the occurrence of multiple organ dysfunction syndrome (MODS) can be reduced by strengthening the stomach and spleen through increasing lucidity and decreasing turbidity. If MODS occurs, CHM can also be used to fight against septic shock and even organ dysfunction [16].

Based on the characteristics of emergency medicine in China, the Preventing Sepsis Campaign in China (PSCC) was initiated in May 2018 [17]. It was advocated by experts that the prevention, diagnosis, and treatment of sepsis should be performed as early as possible to decrease morbidity and mortality, and the principle of the prevention of sepsis was introduced to prevent its occurrence. Several Chinese treatment guidelines for sepsis management and expert consensus-e.g., the Chinese guidelines for the emergency management of sepsis and septic shock 2018, the clinical practice guidelines on traditional Chinese medicine therapy alone or combined with antibiotics for sepsis, and the Chinese emergency medicine expert consensus on the diagnosis and treatment of sepsis complicated by disseminated intravascular coagulation - have been successively released for the management of sepsis [16-18]. In these treatment guidelines and expert agreements, CHMs are recommended as add-on therapies to complement the conventional treatment of sepsis, e.g., a XueBijing injection (XBJ) for sepsis, a ShenFu injection (SF) for septic shock, the ShengMai formula (SMF) for sepsis with the qi and yin exhaustion pattern, the Xuanbai Chengqi decoction (XBCQ) for sepsis with acute respiratory distress syndrome (ARDS), the Qingwen Baidu decoction (QWBD) for sepsis with the internal exuberance of toxins and heat pattern, etc. [15]. The diagnosis and treatment protocol for COVID-19 (the revised eighth version) released by China's National Health Commission also recommends the use of CHM in accordance with different degrees of severity of COVID-19 [19]. XueBiJing, ShenFu, and ShengMai injections are typical herbal injections officially recommended for the management of COVID-19 when patients with a severe case of the disease develop SIRS and/or MODS [19].

Although CHMs have been widely used in the clinic for the treatment of sepsis, their material bases and underlying mechanisms of action have not yet been well defined. Here, we summarize the research progress for several of the most frequently used antisepsis 
CHM, including their clinical efficacy, pharmacodynamics, mechanisms of action, phytochemistry, and pharmacokinetics. This review provides a theoretical basis for their clinical application and provides important information for further clarifying the material bases of such medicines, aiming to provide potential bioactive and bioavailable compounds for developing novel antisepsis drugs.

\section{Chinese Herbal Medicines}

\subsection{Chinese Patent Medicines}

\subsubsection{XueBiJing Injection}

The XueBiJing injection (XBJ), derived from the Xuefu Zhuyu decoction, is an injectable licensed in China since 2004 for sepsis and MODS, with a National Medical Products Administration (NMPA) drug ratification number of GuoYaoZhunZi-Z20040033. It is exclusively manufactured by Tianjin Chasesun Pharmaceutical (Tianjin, China). The herbal injection is prepared from a combination of Carthamus tinctorius flower (Honghua in Chinese), Paeonia lactiflora root (Chishao), Salvia miltiorrhiza root (Danshen), Ligusticum chuanxiong rhizome (Chuanxiong), and Angelica sinensis root (Danggui). Several metaanalyses have suggested that the addition of XBJ to routine sepsis care could further reduce the 28-day mortality of patients and incidence of complications, and improve patient prognosis [20-24]. The 28-day mortality is the primary clinical outcome of sepsis care. In a prospective, randomized controlled trial in 710 patients with severe community-acquired pneumonia, adding XBJ to the conventional treatment reduced the 28-day mortality from $24.6 \%$ (conventional treatment) to $15.9 \%$ (conventional treatment $+\mathrm{XBJ}$ ), increased the percentage of patients with improved pneumonia severity indices from $46.3 \%$ to $60.8 \%$, and improved their Sequential Organ Failure Assessment (SOFA) scores from 4.44 to 3.65 and Acute Physiology and Chronic Health Evaluation (APACHE) II scores from 11.12 to 9.19 ( $p<0.01$ for all) [25]. In a single-center, randomized, double-blinded, prospective trial in 60 patients with severe COVID-19, significant improvements in the rates of septic shock and mechanical ventilation, as well as the proportion of patients severely affected, the duration until the main clinical symptoms improved ( $p<0.05$ for all), and the lengths of ICU hospitalization $(p<0.01$ ), were observed for the XBJ group (routine medication $+\mathrm{XBJ}$ ) after 14 days of treatment, compared with the control group (routine medication + saline) [26]. A large-scale survey involving 31,913 hospitalized patients indicated that the incidence of adverse drug reactions (ADRs) to XBJ was at the occasional level (0.3\%); most of these reactions were mild or nonserious [27]. Another analysis of data from the Hospital Information System indicated that the ADRs to XBJ were mainly correlated with age, dosage, vehicle type, and drug combination [28]. A recent investigation by our group suggested that the herbal compounds in XBJ have a low potential to participate in therapeutic pharmacokinetic interactions with antibiotics when coadministered with XBJ in sepsis care [29].

Many pharmacological studies have suggested that the antisepsis action of $\mathrm{XBJ}$ is correlated with the modulation of the host response, i.e., inhibiting the uncontrolled release of inflammatory mediators, relieving an early overabundant innate immune response and potentially cumulative immunosuppression, attenuating crosstalk between inflammation and coagulation, protecting endothelial cells, and maintaining the physiologic functions of vital organs [30-33]. Zhou et al. identified four biological functional actions of XBJ in sepsis: the regulation of inflammation, immune activity, cell apoptosis, and coagulation [34]. XBJ can significantly alleviate liver injury in cecal ligation and puncture (CLP) rats via downregulating tumor necrosis factor- $\alpha$ (TNF- $\alpha$ ) and interleukin 6 (IL-6) expression while upregulating IL-10 expression and promoting the suppression of cytokine signaling 1 (SOCS1) expression [35]. XBJ played a protective role in methicillin-resistant Staphylococcus aureus (MRSA)-challenged mice by downregulating the inflammatory response (IL-6, TNF$\alpha$, IL-1 $\beta$, and IL-12) and signaling pathways (NF-KB, MAPK, and PI3K/Akt) activated by Pam3CSK4 (a synthetic tripalmitoylated lipopeptide mimicking bacterial lipoproteins) [36]. A study based on a sepsis rat model indicated that adding XBJ to antibiotics could improve 
renal perfusion and oxygenation and suppress renal inflammation, as well as ameliorate kidney dysfunction [37]. A rat- and cell-based study indicated that XBJ may improve pulmonary vascular barrier function by upregulating claudin- 5 expression in a rat model with acute lung injury (ALuI) [38]. A GC/MS-based metabonomics approach revealed that $\mathrm{XBJ}$ reduced multiorgan dysfunctions in septic rats and increased their survival rate: serum biochemistry indicators including blood urea nitrogen $(\mathrm{BUN})$, creatinine $(\mathrm{Cr})$, alanine aminotransferase (ALT), and aspartate aminotransferase (AST); cytokines (TNF- $\alpha$ and IL-6); and morphologic changes all decreased [39].

XBJ may improve the clinical symptoms and alleviate the disease severity of COVID19. By using network pharmacology and molecular docking analysis approaches, the active ingredients, potential molecular targets, and mechanisms of XBJ have been investigated [40,41]. Similarly, to explore the multicomponent, multipathway, and multitarget mechanisms of XBJ in sepsis, a drug-target-pathway network and a drug-ingredients-targets-disease network of XBJ were constructed by Zuo et al. and Feng et al., respectively, to identify major active ingredients, targets, and signaling pathways [42,43].

$\mathrm{XBJ}$ is a chemically complex herbal injection; more than 100 constituents, including Honghua flavonoids, Chishao monoterpene glycosides, Danshen catechols, Chuanxiong/Danggui phthalides, and other types of constituents, have been detected and characterized in XBJ $[29,44]$. Additionally, several analytical assays have been developed for the quantification of the multiple constituents in XBJ [44-48]. Based on the comprehensive chemical composition analysis of XBJ, the human pharmacokinetics of XBJ (by dosing with labeled doses) were systematically investigated by Li et al., and the disposition of major circulating XBJ compounds was well characterized with supportive rat studies and in vitro metabolism and transport studies [29,49-51]. Accordingly, 13 major circulating XBJ compounds originating from the five component herbs were identified, i.e., hydroxysafflor yellow A from Honghua; paeoniflorin, oxypaeoniflorin, and albiflorin from Chishao; senkyunolide I, senkyunolide I-7-Oâ-glucuronide, senkyunolide $\mathrm{G}$, and ferulic acid from Chuanxiong and Danggui; tanshinol, 3-Omethyltanshinol, protocatechuic acid, salvianolic acid B, and 3-O-methylsalvianolic acid B from Danshen. Among these compounds, senkyunolide I-7-O-â-glucuronide, 3-O-methyltanshinol, protocatechuic acid, and 3-O-methylsalvianolic acid $\mathrm{B}$ are the in vivo metabolites of senkyunolide I, tanshinol, protocatechuic aldehyde, and salvianolic acid B, respectively; the unchanged compound protocatechuic aldehyde could not be detected in human plasma samples [29,49-51]. Several other research groups also measured circulating herbal compounds in their unchanged forms in rats receiving XueBijing based on developed bioanalytical assays [52-55]. Zuo et al. investigated the tissue distributions of several bioactive compounds in rats after they intravenously received XBJ, and the levels of exposure to four compounds (i.e., hydroxysafflor yellow A, paeoniflorin, ferulic acid, and benzoylpaeoniflorin) were found to be high in the kidneys, liver, stomach, and intestines [52]. Hydroxysafflor yellow A, despite its poor membrane permeability, could partly cross the damaged blood-brain barrier in patients with traumatic brain injury after the intravenous administration of XBJ [56].

The antisepsis-related activities-i.e., anti-inflammatory, anticoagulant, endotheliumprotective, immune-regulatory, antioxidant, and organ-protective activities-of the aforementioned unchanged circulating compounds from XBJ, based on animal or cellular studies, have been widely reported [57-64]. However, the experimental doses or concentrations of the test XBJ compounds were poorly related to their systemic exposure levels. Therefore, the antisepsis-related activities of the major pharmacokinetically identified circulating compounds were systematically evaluated at the concentrations of their systemic exposure levels after dosing XBJ in in vitro studies and for individual doses of XBJ in a CLP rat study. Finally, six XBJ compounds (hydroxysafflor yellow A, paeoniflorin, oxypaeoniflorin, albiflorin, tanshinol, and senkyunolide I; Figure 1) were identified to be the material basis of XBJ: the survival rate of CLP rats receiving the intravenous injection of the combination of the six XBJ compounds proved to be comparable to that of CLP rats receiving XBJ. The survival rates of both groups were significantly lower than that of CLP control rats 
receiving $0.9 \%$ saline ( $p<0.05$; pending publication). Table 1 lists some potential target pathways of the bioavailable and bioactive XBJ compounds.

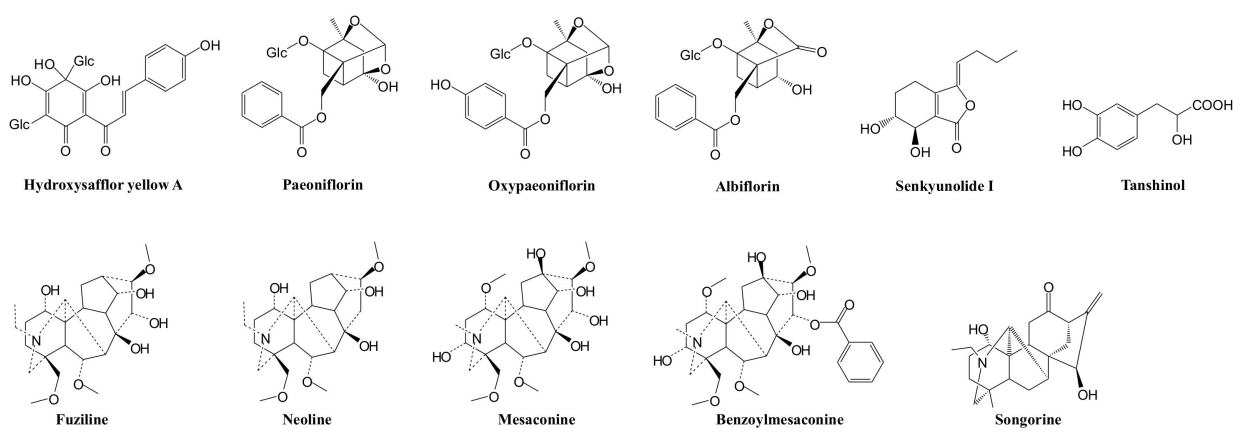

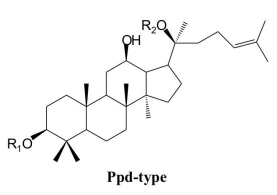

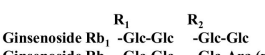
$\begin{array}{lll}\text { Ginsenoside } R b_{1}-\text { Glc-Glc } & \text {-Glc-Glc } \\ \text { Ginsenoside } \mathrm{Rb}_{2} \text {-Glc-Glc } & \text {-Glc-Ara (p) } \\ \text { Ginsenoside } R c & \text {-Glc-Glc } & \text {-Glc-Ara (f) }\end{array}$ Ginsenoside Rd -Glc-Glc -Glc

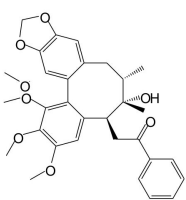

Schisantherin A
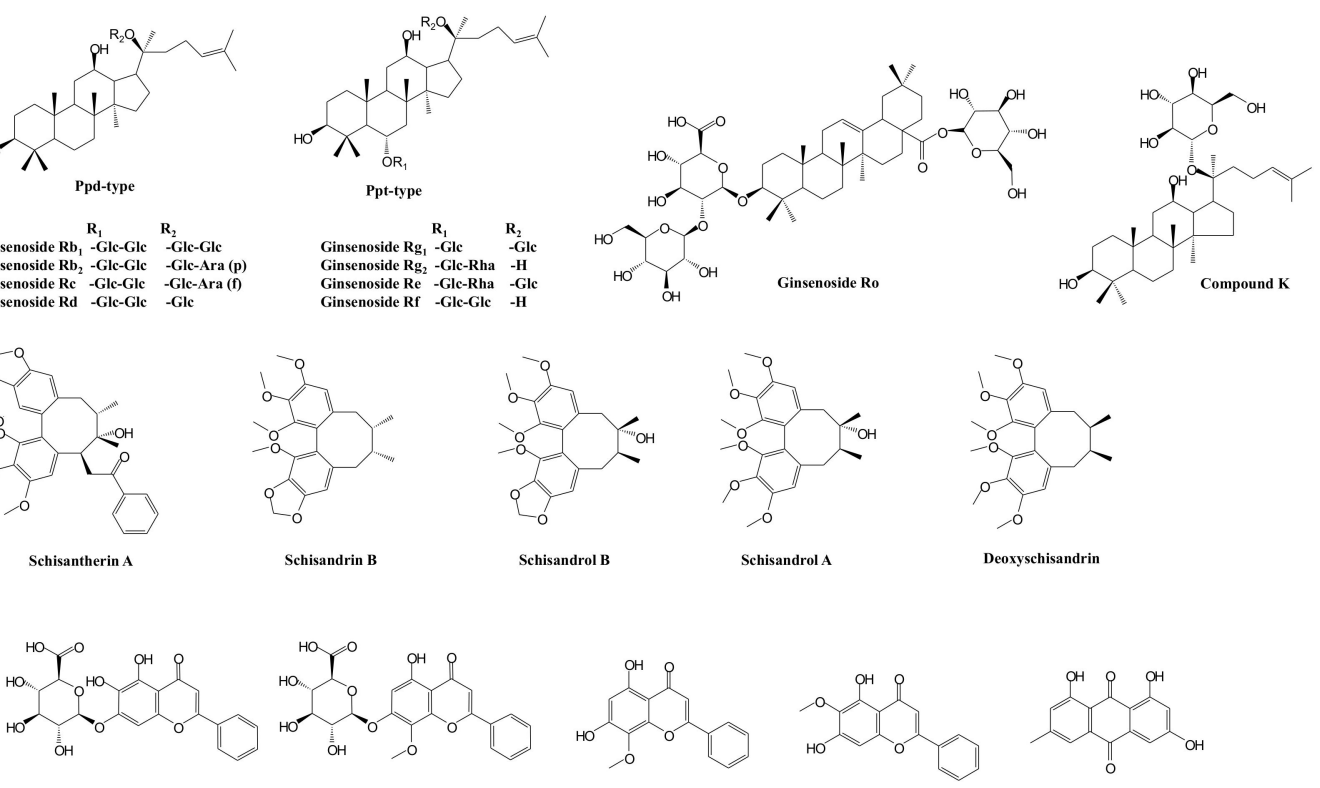

Baicalin

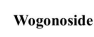

Wogonin

Oroxylin A

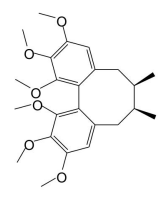

Deoxyschisandrin
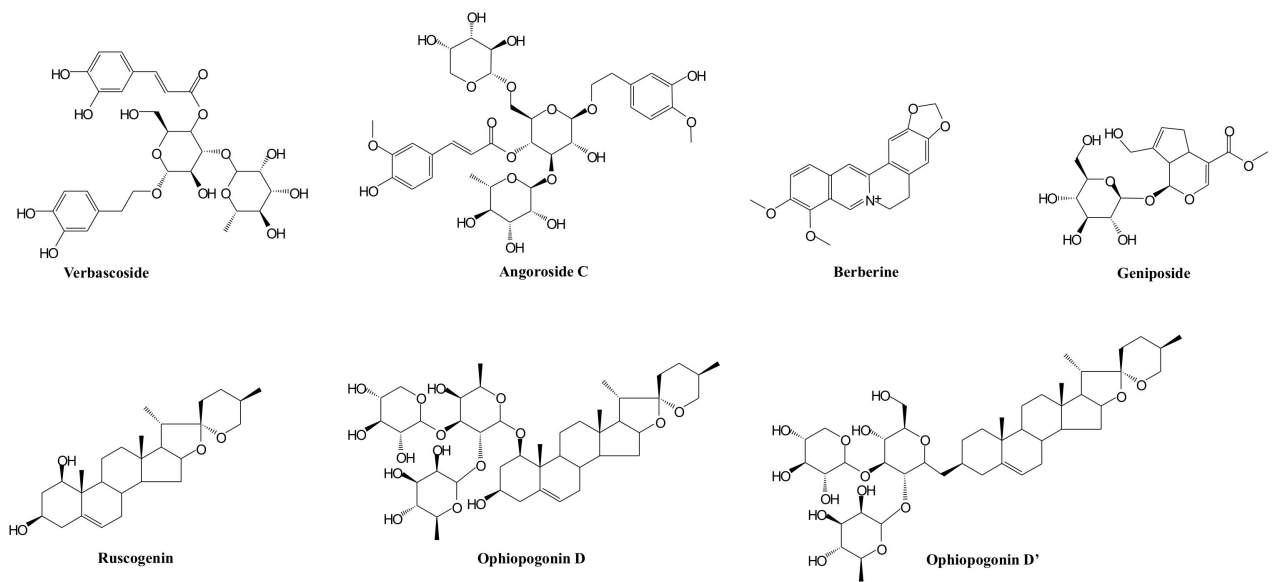

Figure 1. Chemical structures of bioactive and bioavailable herbal compounds from antisepsis Chinese herbal medicines.

\subsubsection{ShenFu Injection}

The ShenFu injection (SF), derived from the ShenFu decoction, is a standardized intravenous herbal medicine prepared from a combination of Panax ginseng steamed root (Hongshen) and processed Aconitum carmichaelii lateral root (Fuzi). It is manufactured by Ya'an Sanjiu Pharmaceutical (Ya'an, Sichuan Province, China) with an NMPA drug 
ratification number of GuoYaoZhunZi-Z51020664. As an emergency medicine, SF is commonly applied in combination with chemotherapy to fight against shock, acute myocardial dysfunction, chronic congestive heart failure, etc. [65-68]. By supplying qi and strengthening yang in terms of traditional Chinese medicine (TCM) theory, SF is widely used for the treatment of Yin-yang Jutsu syndrome and severe deficiency syndromes with signs of hidrosis, mental exhaustion, breathlessness, uroclepsia, a weak pulse, etc. [15].

For septic shock patients, the TCM syndrome score facilitates the evaluation of the effect of the TCM syndrome and the construction of a treatment plan. Based on this strategy, the combination of SF with standard bundle therapy significantly improved patients' circulation, tissue perfusion, and coagulation function, as well as inflammation reactions [69]. Adding SF to conventional therapy could increase patients' mean arterial pressure (MAP), normalize the heart rate, clear serum lactate, and reduce the mortality of patients, thus reducing the occurrence of septic shock and the need for resuscitation [70,71]. Based on a systematic review and meta-analysis of randomized controlled trials, compared with standard therapy, the addition of SF showed a trend of decreasing 28-day mortality $(p=0.17)$ only for the septic shock patients, with $4.5 \mathrm{mmol} / \mathrm{L} \leq$ mean arterial lactate level $<7 \mathrm{mmol} / \mathrm{L}$ and with a yang-qi deficiency (a TCM syndrome) [72]. A multicenter, randomized, controlled, open-labeled trial carried out in 210 patients with septic shock in China suggested that adding SF to the conventional treatment further improved the 7 -day survival rate $(83.3 \%$ versus $54.5 \%, p=0.034)$ in patients with impaired lactate clearance $(\geq 4.5 \mathrm{mmol} / \mathrm{L})$ [73]. SF can enhance the cellular immunity of patients with septic shock by increasing CD4+ and CD8+ T cells in the peripheral blood and upregulating human leukocyte antigen-DR (HLA-DR) expression in monocytes. SF was also found to restore ex vivo monocytic TNF- $\alpha$ and IL-6 proinflammatory cytokine release in response to endotoxins. In addition, patients in the SF group $(n=78)$ showed better clinical outcomes than those in the placebo group $(n=79)$ in terms of the APCHE II score $(13.2 \pm 7.6 \mathrm{vs}$. $16.9 \pm 8.8 ; p=0.034)$, the Marshall score ( $6.8 \pm 2.6$ vs. $8.5 \pm 3.3 ; p=0.01)$, the duration of vasopressor use ( $2.5 \pm 1.5$ vs. $3.7 \pm 1.7$ days; $p=0.008)$, and the length of ICU stay (10.5 \pm 3.2 vs. $12.2 \pm 2.8$ days; $p=0.012$ ) [74]. A clinical investigation in 89 elderly patients with severe pneumonia indicated that compared with the control group, the serum levels of TNF- $\alpha$, IL-6, and IL-8 after 7-day treatment with SF significantly decreased $(p<0.05)$, while the serum level of IL-10 obviously increased $(p<0.05)$. The APACHE II score was significantly lower than that before the treatment (it decreased from $17.4 \pm 3.2$ to $8.6 \pm$ $3.5 ; p<0.05)$, whereas the application time for vasoactive drugs, the time of mechanical ventilation, and the duration in the ICU were notably shortened $(p<0.05)$ [75]. 
Table 1. Chemical compositions, pharmacological actions, bioactive compounds, and mechanisms of action of representative antisepsis Chinese herbal medicines

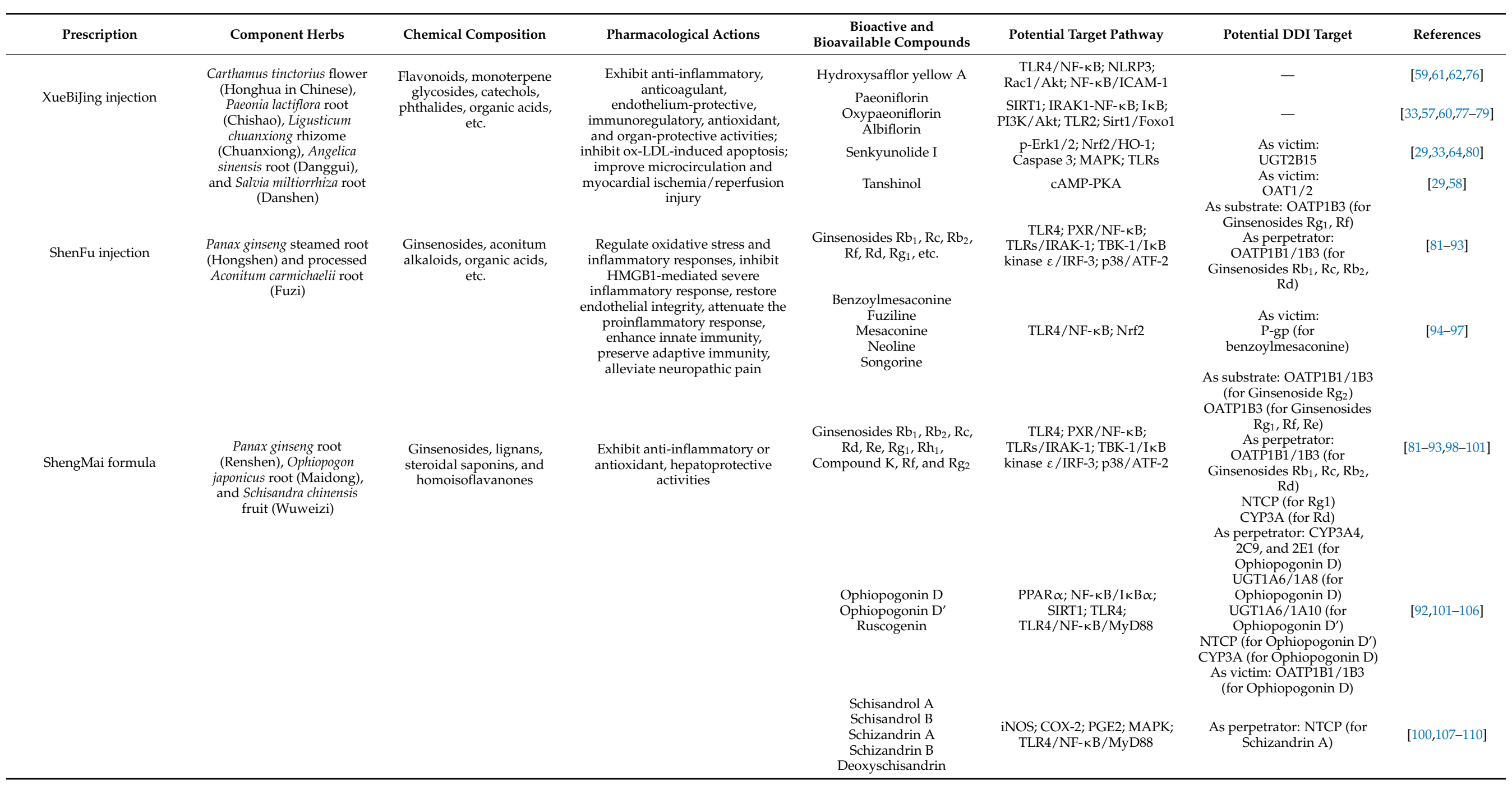


Table 1. Cont.

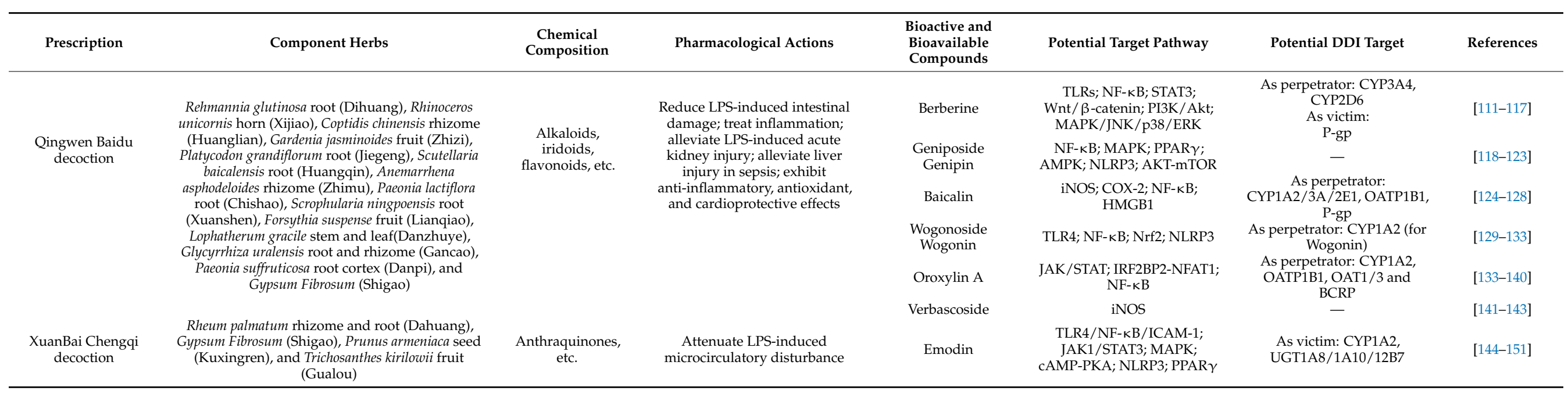


SF has been widely used in clinical patients since it became available on the market in 1987, and all the reported side effects are mild [152]. In safety monitoring for SF involving 30,106 patients, adverse drug events (ADEs) occurred in only 114 patients, and ADRs occurred in only 23 patients, showing a rare-level incidence rate of $0.076 \%$ [153].

Gastrointestinal mucosal injury and gastrointestinal dysfunction in patients with sepsis indicate the aggravation of sepsis or that the prognosis is worsening [154,155]. Xing et al. reported the protective effect of SF on the intestinal mucosal barrier in a rat model of sepsis, with intestinal mucosal disruption accompanied by accelerated apoptosis of the epithelial cells, leading to bacterial translocation and progression to multiple organ dysfunction $[156,157]$. The rats administered a low $(5 \mathrm{~mL} / \mathrm{kg})$ or high $(20 \mathrm{~mL} / \mathrm{kg})$ dose of SF showed lower mortality, lower intestinal mucosal injury, and lower serum TNF- $\alpha$ and IL-6 levels $(p<0.05)$, as well as higher secretory immunoglobulin A (sIgA) levels and CD3 and $\gamma \delta \mathrm{T}$ cell numbers $(p<0.01)$, than the model group, in a dose-dependent manner [158]. SF also exerted a protective effect on lipopolysaccharide (LPS)-induced septic shock in rabbits by increasing MAP; decreasing serum lactate dehydrogenase (LDH) and AST levels; improving the heart, liver, and kidney morphology of LPS-induced rabbit models with septic shock [159]. SF attenuated the inflammation and apoptosis induced by LPS in rats via downregulating the mitogen-activated protein kinase (MAPK) and extracellular regulated protein kinase signaling pathways [160]. SF suppressed sepsisinduced myocardial apoptosis and injury by upregulating the protein expression of B-cell lymphoma 2; downregulating that of $\mathrm{BH} 3$ interacting-domain death agonist, truncated-Bid, and caspase-9 $(p<0.05)$; and alleviating mitochondrial damage [161]. The levels of several biomarkers (TNF- $\alpha$, the ileal malondialdehyde level, the apoptosis index for ileal mucosal epithelial cells, and the Bax protein level) were significantly higher in the CLP group than in the sham group $(p<0.01$ or $p<0.05)$, while some others (the serum level of IL-10, $\mathrm{Bcl}-2 / \mathrm{Bax}$ ratio, $\mathrm{Bcl}-2$ protein level, and occludin protein level) were significantly lower. Both low-dose $(5 \mathrm{~mL} / \mathrm{kg})$ and high-dose $(10 \mathrm{~mL} / \mathrm{kg}) \mathrm{SF}$ significantly ameliorated these changes $(p<0.01$ or $p<0.05)$ in a dose-dependent manner [162]. SF also dose-dependently prevented MAP drop, relieved lung damage, and increased the survival rate in the rat model of endotoxin shock, perhaps through inhibiting the high-mobility group protein B1 (HMGB1)-nuclear factor $\mathrm{\kappa B}(\mathrm{NF}-\mathrm{\kappa B})$ pathway, thus preventing a cytokine storm [163].

SF contains multiple herbal constituents, including ginsenosides (originating from Hongshen), aconitum alkaloids (from Fuzi), and organic acids (mainly from Fuzi) [164,165]. Yang et al. detected 44 herbal constituents (i.e., 19 ginseng saponins, 1 panaxytriol, 1 5-hydroxymethylfurfural, and 23 trace diterpene alkaloids) in SF and quantified 24 major ginsenosides and alkaloids. The total concentrations of saponins and alkaloids were 676-742 $\mu \mathrm{g} / \mathrm{mL}$ and 3-7 $\mu \mathrm{g} / \mathrm{mL}$, respectively, in five batches of SF samples. The ginsenosides $\mathrm{Rb}_{1}$ and $\mathrm{Rg}_{1}$ were higher in content than other constituents, i.e., $176.4 \pm 1.4$ $\mu \mathrm{g} / \mathrm{mL}(159.0 \mu \mathrm{mol} / \mathrm{L})$ and $120.0 \pm 1.3 \mu \mathrm{g} / \mathrm{mL}(149.9 \mu \mathrm{mol} / \mathrm{L})$, respectively. In addition, a high batch-to-batch quality consistency for SF samples was observed [166]. In addition to hydrophobic aconite alkaloids and ginsenosides, another 157 hydrophilic compounds (154 compounds identified as amino acids, nucleosides, organic acids, carbohydrates, etc.; 3 compounds unknown) were detected in SF by Song et al. In addition, 40 primary hydrophilic and hydrophobic ingredients (11 ginsenosides, 9 aconite alkaloids, 11 amino acids, and 9 nucleosides) were quantitatively or semi-quantitatively analyzed, and the mean contents of the ginsenosides $\mathrm{Rb}_{1}(129.3 \mu \mathrm{g} / \mathrm{mL} ; 116.6 \mu \mathrm{mol} / \mathrm{L})$ and $\operatorname{Rg}_{1}(97.1 \mu \mathrm{g} / \mathrm{mL} ; 121.3 \mu \mathrm{mol} / \mathrm{L})$ in SF were also found to be much higher than those of the aconite alkaloids songorine $(0.13$ $\mu \mathrm{g} / \mathrm{mL} ; 0.36 \mu \mathrm{mol} / \mathrm{L})$, benzoylmesaconine $(2.43 \mu \mathrm{g} / \mathrm{mL} ; 4.12 \mu \mathrm{mol} / \mathrm{L})$, benzoylhypaconine $(0.60 \mu \mathrm{g} / \mathrm{mL} ; 1.05 \mu \mathrm{mol} / \mathrm{L})$, and hypaconitine $(0.02 \mu \mathrm{g} / \mathrm{mL} ; 0.03 \mu \mathrm{mol} / \mathrm{L})$ [167]. On the basis of in vitro and in silico studies, Li et al. identified some NF- $\mathrm{kB}$ inhibitors for counteracting inflammation in SF such as 20(S)-protopanaxadiol type (ppd-type) glycosides (ginsenosides $\mathrm{Rb}_{1}, \mathrm{Rb}_{2}, \mathrm{Rb}_{3}$, $\mathrm{Rc}$, and $\mathrm{Rd}$ ), 20(S)-protopanaxatriol type (ppt-type) glycosides 
(ginsenosides $\operatorname{Rg}_{1}, \mathrm{Rg}_{2}, \mathrm{Re}, \mathrm{Rf}$, and $\mathrm{F}_{1}$ ), diester-type alkaloids (fuziline and neoline), and aconine derivatives (mesaconine and benzoylmesaconine) [168].

After intravenously administrating SF to rats at a dosage of $5.0 \mathrm{~mL} / \mathrm{kg}$, the systemic exposure to the ppd-type ginsenosides $\mathrm{Rb}_{1}, \mathrm{Rc}$, and $\mathrm{Rb}_{2}$ in rat plasma (64.3 $\pm 28.1,60.5 \pm$ 26.9 , and $41.2 \pm 18.8 \mu \mathrm{mol} \cdot \mathrm{h} / \mathrm{L}$, respectively) was much higher than that to the ppt-type ginsenosides $\mathrm{Rf}$ and $\mathrm{Rd}(5.47 \pm 4.12$ and $2.97 \pm 2.13 \mu \mathrm{mol} \cdot \mathrm{h} / \mathrm{L}$, respectively), which is probably because $\mathrm{Rb}_{1}$, $\mathrm{Rc}$, and $\mathrm{Rb}_{2}(0.59,0.53$, and $0.39 \mu \mathrm{mol} / \mathrm{kg}$, respectively) had higher contents than $\mathrm{Rf}$ and $\mathrm{Rd}(0.12$ and $0.86 \mu \mathrm{mol} / \mathrm{kg}$, respectively) and also had much longer half-life $t_{1 / 2}(19.3 \pm 6.4,29.5 \pm 22.9$, and $35.6 \pm 30.7 \mathrm{~h}$, respectively) than $\mathrm{Rf}$ and $\mathrm{Rd}(4.21$ \pm 3.68 and $8.49 \pm 5.20 \mathrm{~h}$, respectively) [169]. The short $t_{1 / 2}$ of ppt-type ginsenosides was mainly attributed to transporter-mediated rapid biliary excretion [91,170]. After a single intravenous bolus of SF at $2 \mathrm{~mL}$ in Wistar rats $(10 \mathrm{~mL} / \mathrm{kg})$, the $t_{1 / 2 \alpha}$ of $\mathrm{Rd}, \mathrm{Rg}_{1}$, $\mathrm{Rb}_{1}$, Ro, $\mathrm{Rc}$, and $\mathrm{Rb}_{2}$ was $0.32 \pm 0.25,0.11 \pm 0.04,0.30 \pm 0.24,0.11 \pm 0.02,0.24 \pm 0.19$, and $0.23 \pm 0.12 \mathrm{~h}$, respectively; the $t_{1 / 2 \beta}$ was $10.25 \pm 0.39,21.31 \pm 3.64,13.95 \pm 2.56$, and $15.06 \pm 1.54 \mathrm{~h}$, respectively; the systemic exposure to $\mathrm{Rd}, \mathrm{Rg}_{1}, \mathrm{Rb}_{1}, \mathrm{Ro}, \mathrm{Rc}$, and $\mathrm{Rb}_{2}$ in rats was $879.8 \pm 137.3,8.07 \pm 1.56,1742.4 \pm 343.6,6.77 \pm 0.58,1001.5 \pm 125.2$, and $1533.7 \pm 229.0 \mu \mathrm{mol} \cdot \mathrm{h} / \mathrm{L}$, respectively [171]. Ginsenosides $\left(\mathrm{Rg}_{1}, \mathrm{Rb}_{1}\right.$, and $\left.\mathrm{Rc}\right)$ and aconitum alkaloids (benzoylmesaconine and fuziline) were detected in dog plasma after the intravenous drip administration of 2,4 , or $8 \mathrm{~mL} / \mathrm{kg}$ of SF. The maximum plasma concentrations $\left(C_{\max }\right)$ of the five analytes were achieved at the point of infusion completion after the single-dose administration of SF, i.e., $T_{\max }$ as $1 \mathrm{~h}$. The plasma $t_{1 / 2}$ was short for benzoylmesaconine and fuziline (approximately 5 and $2 \mathrm{~h}$, respectively); this relative rapid elimination makes them relatively safe for clinical use due to the two alkaloids' low toxicity. Similarly, the elimination of the ppt-type ginsenoside $\operatorname{Rg}_{1}$ was also quick $\left(t_{1 / 2}\right.$, less than $0.5 \mathrm{~h}$ ), while the elimination of the ppd-type ginsenosides $\mathrm{Rb}_{1}$ and $\mathrm{Rc}$ was much slower (70 and $90 \mathrm{~h}$, respectively), which facilitates maintaining effective systemic exposure levels and achieving better therapeutic effects. After the intravenous infusion of SF in beagles, the plasma concentrations of the five analytes all increased proportionally over the dosage range of 2-8 $\mathrm{mL} / \mathrm{kg}$ [172]. The chemical structures of major circulating SF compounds are shown in Figure 1, and their potential action target pathways are summarized in Table 1.

\subsection{Chinese Herbal Prescriptions \\ 2.2.1. ShengMai Formula}

The ShengMai formula (SMF), which was first recorded in Yi Xue Yuan Li, consists of P. ginseng root (Renshen), Ophiopogon japonicus root (Maidong), and Schisandra chinensis fruit (Wuweizi) with a dosage proportion of 5:3:1.5. It is normally prepared as ShengMai powder (SMP; or ShengMai san, SMS), ShengMai yin (SMY), ShengMai injection (SMI), etc., for clinical use. SMF is a classic tonic prescription for the treatment of tuberculosis, chronic bronchitis, cough due to neurasthenia, and heart failure [173]. SMI, an intravenous dosage form of SMF, is used to treat acute myocardial infarction, cardiogenic shock, toxic shock, hemorrhagic shock, coronary heart disease, endocrine disorders, and other diseases due to a deficiency of qi and yin, with low toxicity [174,175]. SMI is highly recommended for use in combination with antibiotics for community-acquired pneumonia in clinical guidelines [16]. A meta-analysis including 17 randomized controlled trials (RCTs) and 860 patients with septic shock suggested that adding SMI to conventional Western medicine treatment further reduced the number of ineffective shock treatments $(p<0.0001)$ and reduced the blood lactate concentration at $12 \mathrm{~h}(p<0.001), 24 \mathrm{~h}(p<0.0001)$, and $72 \mathrm{~h}$ $(p=0.002)[176]$.

SMI protects multiple organs by regulating immunity, inflammation, apoptosis, and energy metabolism. SMI also protected the intestinal mucosal barrier of mice mainly through regulating the NF- $\mathrm{KB}$-pro-inflammatory factor-myosin light-chain kinase (MLCK)TJ cascade. Decreasing trends for inflammatory factors including interferon- $\gamma($ IFN- $\gamma)$, TNF- $\alpha$, and IL-2 were observed in the sera of mice receiving SMI at $1.5 \mathrm{~mL} / \mathrm{kg}$. The content of occludin increased and MLCK protein decreased in SMI-treated mice compared 
with the endotoxemia mouse model group $(p<0.05$ or $p<0.01)$ [177]. SMI could induce myocardial mitochondrial autophagy via the caspase-3/Beclin-1 axis to protect myocardial mitochondria in septic mice [178]. A study by Chai et al. on CLP rats suggested that the regulation of taurine and taurine metabolism, as well as arginine and proline metabolism, etc., could be the key mechanism in the treatment of sepsis [179].

Zheng et al. recently reviewed, in Chinese, the material composition, preclinical pharmacokinetic, and pharmacodynamic studies of SMI [180]. Several research groups have analyzed the chemical compositions of SMF preparations and identified the main constituents as ginsenosides (originating from P. ginseng), steroidal saponins (from O. japonicus), lignans (from S. chinensis), and flavonoids (mainly from O. japonicus). Using LC-IT-TOF/MS and a diagnostic fragment-ion-based extension strategy, Zheng et al. detected and identified more than 30 ginsenosides and 20 lignans from SMI [181]. Zhao et al. identified or partially characterized 87 herbal compounds in SMI and selected 6 bioactive constituents (four ginsenosides (i.e., $\operatorname{Rg}_{1}, \operatorname{Re}, \mathrm{Rb}_{1}$, and $\mathrm{Rd}$ ) and 2 lignans (i.e., schisandrol $\mathrm{A}$ and schisandrol B) with high content levels as quality markers (Q-markers). The total content range for these selected Q-markers in 10 batches of SMI was 13.8-22.5 mg/mL [182]. Wu et al. identified 92 compounds (i.e., 49 ginsenosides, 31 lignans, 5 steroidal saponins, and 7 homoisoflavanones) in SMP and discovered a class of 25-hydroxyginsenosides for the first time [183]. In a study by Cheng et al., 10 compounds (the ginsenosides $\mathrm{Rb}_{1}, \mathrm{Rb}_{2}, \mathrm{Rc}$, $\mathrm{Rd}, \mathrm{Re}, \mathrm{Rg}_{1}$, and $\mathrm{Rh}_{1}$; compound $\mathrm{K}$; ophiopogonin $\mathrm{D}$; and schisandrol A) were measured in SMP, and the contents of these herbal constituents were found to vary by up to several hundredfolds among five pharmaceutical manufacturers [184]. In their study, Zheng et al. selected eight compounds (the ginsenosides $\mathrm{Rf}, \mathrm{Rb}_{1}, \mathrm{Rg}_{2}$, and $\mathrm{Rb}_{2}$; schisandrol $\mathrm{A}$; schisandrol B; methylophiopogonanone A; and schisandrin B) as Q-markers to evaluate the batch-to-batch consistency of SMF; ginsenoside $\mathrm{Rb}_{1}$, ranging from $2046.1 \mu \mathrm{g} / \mathrm{g}(1.84$ $\mu \mathrm{mol} / \mathrm{g})$ to $5975.8 \mu \mathrm{g} / \mathrm{g}(5.39 \mu \mathrm{mol} / \mathrm{g})$, was found to be the dominant component in SMF, followed by ginsenoside $\mathrm{Rg}_{2}(838.3-2091.64 \mu \mathrm{g} / \mathrm{g} ; 1.07-2.66 \mu \mathrm{mol} / \mathrm{g})$ and ginsenoside $\mathrm{Rb}_{2}$ (567.2-1989.9 $\mu \mathrm{g} / \mathrm{g} ; 0.53-1.84 \mu \mathrm{mol} / \mathrm{g})$. The batch-to-batch chemical variation among 10 batches of SMF ranged from $27.9 \%$ (for ginsenoside Rf) to $113.95 \%$ (for schisandrol B) [185]. Li et al. established a seven-marker-based quality standard to quantify seven ginsenosides (i.e., the ginsenosides $\mathrm{Rf}, \mathrm{Rd}, \mathrm{Rc}, \mathrm{Re}, \mathrm{Rb}_{1}, \mathrm{Rb}_{2}$, and $\mathrm{Rg}_{1}$ ) in $\mathrm{SMI}$, which was then used to evaluate the quality consistency of 22 batches of SMI [186]. Li et al. detected 62 compounds in SMI and established a quantitative assay for the determination of 21 main components, including 14 saponins, 6 lignans, and 1 pyranoglucoside, and found the contents of these 21 components to vary widely amongst 10 batches [187].

Lu et al. established a TCM-components-core targets-key pathway network platform to investigate the mechanism of SMI's effects in sepsis. SMI was found to mainly affect several signaling pathways, suggesting that SMI could regulate immunity, inflammation, apoptosis, and energy metabolism for the protection of multiple organs. Gene ontology (GO) enrichment analysis further indicated that the bioactive SMI constituents altered the pathophysiology of sepsis through the regulation of various biological processes [188]. SMP protected against I/R-induced blood-brain barrier (BBB) dysfunction by significantly upregulating ZO-1 and claudin-5 under oxygen-glucose deprivation/reoxygenation (OGD/R), as well as reducing matrix metalloproteinase 2/9 (MMP-2/9) levels and the phosphorylation of myosin light-chain (MLC) through the ROCK/cofilin signaling pathway [189].

Zhan et al. developed and validated a sensitive LC-MS/MS method for the simultaneous quantification of 11 SMI compounds in rat serum and applied it to a pharmacokinetic study in rats after a single intravenous administration of SMI. The 11 constituents were ppt-type ginsenosides (i.e., the ginsenosides $\operatorname{Rg}_{1}$, $R e, R f$, and $\mathrm{Rg}_{2}$ ), ppd-type ginsenosides (i.e., the ginsenosides $\mathrm{Rb}_{1}, \mathrm{Rd}$, and $\mathrm{Rc}$ ), ophiopogonin (ophiopogonin $\mathrm{D}$ ), and lignans (i.e., schisandrol A, schisandrol B, and schisandrin B) [190,191]. A total of 30 compounds (23 prototype components and 7 metabolites) were detected and characterized in the plasma of rats after they received SMS $(8 \mathrm{~g} / \mathrm{kg})[192,193]$. Further, ppt-type ginsenosides were 
eliminated rapidly through urinary, biliary, and fecal excretions (plasma $t_{1 / 2 \hat{a}}, 0.60-0.82$ $\mathrm{h}$; MRT, $0.22-0.46 \mathrm{~h}$ ), whereas the ppd-type ginsenosides $\mathrm{Rb}_{1}$, $\mathrm{Rd}$, and Rc exhibited slow elimination through biliary and urinary excretions (MRT, 23.0-28.6 h). Ophiopogonin D was mainly excreted in bile in the metabolized forms. Schisandrol A, schisandrol B, and schisandrin B, with low contents in SMI, were found to be eliminated quickly (plasma $t_{1 / 2} \hat{a}, 0.51-1.98 \mathrm{~h}$; MRT, 0.51-2.50 h) and accumulated in these tissues. Lignans were mainly excreted in their metabolized form, as indicated by the very low biliary, urinary, and fecal excretion of the unchanged forms [190,191]. SMI, within the concentration range of 30\% (volume percentage), showed an inhibitory effect on the activities of CYP1A2, CYP2B6, CYP2C8, CYP2C9, CYP2C19, CYP2D6, and CYP3A4, with $\mathrm{IC}_{50}$ values of $6.12 \%, 2.72 \%$, $10.00-30.00 \%, 14.31 \%, 12.96 \%, 12.26 \%$, and $3.72 \%$, respectively, and had an inhibitory effect on the activities of the transporters MDR1, BCRP, and organic anion transporting polypeptide (OATP) $1 \mathrm{~B} 1$, with $\mathrm{IC}_{50}$ values of $0.15 \%, 0.75 \%$, and $2.03 \%$, respectively. This suggested a high risk of drug interactions of SMI when clinically combined with the use of the transporters MDR1 and BCRP substrate [194]. SMS selectively suppressed intestinal, but not hepatic, nifedipine oxidation (a CYP3A marker reaction) activity in a dose- and time-dependent manner. Three-week SMS treatment decreased the maximal velocity of intestinal nifedipine oxidation by $50 \%$, while the CYP3A protein level remained unchanged; among the SMS component herbs, the decoction of Ophiopogonis Radix decreased the intestinal nifedipine oxidation activity [195]. Based on an inhibition kinetic investigation of various UGT isoforms, ophiopogonin D was found to noncompetitively inhibit UGT1A6 $\left(K_{\mathrm{i}}, 20.6 \mu \mathrm{mol} / \mathrm{L}\right)$ and competitively inhibit UGT1A8 $(40.1 \mu \mathrm{mol} / \mathrm{L})$; ophiopogonin D' noncompetitively inhibited UGT1A6 (5.3 $\mu \mathrm{mol} / \mathrm{L})$ and UGT1A10 $(9.0 \mu \mathrm{mol} / \mathrm{L})$; and ruscorectal competitively inhibited UGT1A4 $(0.02 \mu \mathrm{mol} / \mathrm{L})$ [106]. The ginsenoside $\mathrm{Rg}_{1}$, ophiopogon $\mathrm{D}^{\prime}$, and schisandrin A are potential inhibitors of sodium taurocholate co-transporting polypeptide (NTCP) and probably interact with NTCP-modulating clinical drugs. The ginsenoside Re and schisandrin B are potential NTCP substrates, and their NTCP-mediated uptake could be inhibited by other ingredients in SMF [100]. The ginsenosides $\mathrm{Rb}_{2}, \mathrm{Rc}$, $\mathrm{Rg}_{2}, \mathrm{Rg}_{3}, \mathrm{Rd}$, and $\mathrm{Rb}_{1}$ are P-gp substrates, and Schisandra Lignans extract (SLE) was found to significantly enhance the uptake and inhibit the efflux ratio of the ginsenosides $R b_{2}$, $\mathrm{Rc}, \mathrm{Rg}_{2}, \mathrm{Rg}_{3}, \mathrm{Rd}$, and $\mathrm{Rb}_{1}$ in Caco-2 and L-MDR1 cells. Additionally, a rat study showed that a single dose and multiple doses of SLE at $500 \mathrm{mg} / \mathrm{kg}$ could significantly increase the $\mathrm{AUC}_{0-\infty}$ of $\mathrm{Rb}_{2}, \mathrm{Rc}$, and Rd without affecting the $t_{1 / 2}$ [196]. The chemical structures of the major circulating SM compounds are shown in Figure 1, and their potential action target pathways are summarized in Table 1.

\subsubsection{Qingwen Baidu Decoction}

The Qingwen Baidu decoction (QWBD), first recorded in the book Yi Zhen Yi De of the Qing Dynasty, is a famous anti-epidemic TCM prescription [197]. It has been used for the treatment of summer-heat syndrome in epidemic febrile disease in China for many years [198]. It consists of Rehmannia glutinosa root (Dihuang), Rhinoceros unicornis horn (Xijiao), Coptidis chinensis rhizome (Huanglian), Gardenia jasminoides fruit (Zhizi), Platycodon grandiflorum root (Jiegeng), Scutellaria baicalensis root (Huangqin), Anemarrhena asphodeloides rhizome (Zhimu), Paeonia lactiflora root (Chishao), Scrophularia ningpoensis root (Xuanshen), Forsythia suspense fruit (Lianqiao), Lophatherum gracile stem and leaf (Danzhuye), Glycyrrhiza uralensis root and rhizome (Gancao), Paeonia suffruticosa root cortex (Danpi), and Gypsum Fibrosum (Shigao) [197]. Wang et al. proposed a protocol for a systematic review and metaanalysis of QWBD for sepsis [198]. Recently, Wen et al. reviewed the potential therapeutic effect of QWBD against COVID-19 [197]. A promising effect was observed upon adding QWBD to conventional Western medical treatment for 18 patients with pulmonary infection, by Sun et al. [199].

Yu et al. found that QWBD produced anti-inflammatory effects by altering the levels of inflammatory mediators in sepsis rats [200]. Based on a network pharmacology study, QWBD was found to exert antisepsis actions by regulating protein phosphorylation, the cell response to 
cytokine stimulation, cell proliferation, the inflammatory response, the transmembrane receptor protein tyrosine kinase signaling pathway, and cytokine-mediated signaling pathways [201]. Although the phytochemistry of the component herbs Dihuang [202], Xijiao [203], Huanglian [204], Zhizi [121,205], Jiegeng [206], Huangqin [207], Zhimu [208], Chishao [209], Xuanshen [210], Lianqiao [211], Danzhuye [212], Gancao [213], Danpi [214], and Shigao $\left(\mathrm{CaSO}_{4} \cdot 2 \mathrm{H}_{2} \mathrm{O}\right)$ have been widely reported, chemical composition studies of QWBD are limited. A total of 21 compounds from 11 component herbs were detected in QWBD and characterized, among which 15 analytical markers were selected for the quality evaluation of QWBD: baicalin (content level, $563.1-852.8 \mu \mathrm{g} / \mathrm{g}$ or $1.26-1.91 \mu \mathrm{mol} / \mathrm{g})$, wogonoside $(64.9-106.8 \mu \mathrm{g} / \mathrm{g}$ or $0.14-0.23 \mu \mathrm{mol} / \mathrm{g})$, geniposidic acid (10.1-21.1 $\mu \mathrm{g} / \mathrm{g}$ or $0.03-0.06 \mu \mathrm{mol} / \mathrm{g})$, oxypaeoniflorin $(18.2-25.3 \mu \mathrm{g} / \mathrm{g}$ or 0.04 $0.05 \mu \mathrm{mol} / \mathrm{g})$, genipin 1- $\beta$-D-gentiobioside $(25.7-60.7 \mu \mathrm{g} / \mathrm{g}$ or $0.047-0.11 \mu \mathrm{mol} / \mathrm{g})$, geniposide (131.9-396.7 $\mu \mathrm{g} / \mathrm{g}$ or 0.34-1.02 $\mu \mathrm{mol} / \mathrm{g})$, paeoniflorin $(201.2-305.5 \mu \mathrm{g} / \mathrm{g}$ or $0.42-0.64 \mu \mathrm{mol} / \mathrm{g})$, mangiferin (50.6-79.2 $\mu \mathrm{g} / \mathrm{g}$ or $0.12-0.19 \mu \mathrm{mol} / \mathrm{g})$, swertiajaponin (17.9-58.7 $\mu \mathrm{g} / \mathrm{g}$ or $0.037-0.12$ $\mu \mathrm{mol} / \mathrm{g})$, acteoside $(106.8-143.8 \mu \mathrm{g} / \mathrm{g}$ or $0.17-0.23 \mu \mathrm{mol} / \mathrm{g})$, forsythoside A (124.2-261.6 $\mu \mathrm{g} / \mathrm{g}$ or $0.20-0.42 \mu \mathrm{mol} / \mathrm{g})$, berberine hydrochloride $(156.2-654.1 \mu \mathrm{g} / \mathrm{g}$ or $0.42-1.76 \mu \mathrm{mol} / \mathrm{g})$, paeonol $(6.24-18.5 \mu \mathrm{g} / \mathrm{g}$ or $0.038-0.11 \mu \mathrm{mol} / \mathrm{g})$, harpagoside $(3.21-14.1 \mu \mathrm{g} / \mathrm{g}$ or $0.006-0.029 \mu \mathrm{mol} / \mathrm{g})$, and glycyrrhizic acid (46.9-14.1 $\mu \mathrm{g} / \mathrm{g}$ or $0.057-0.16 \mu \mathrm{mol} / \mathrm{g})$. QWBD exhibited potent antiinflammatory effects in a dose-dependent manner based on a study in zebrafish inflammatory models. The mechanism may be related to the activation of the NF- $\mathrm{KB}$ and signal transducer and activator of transcription (STAT)3 signaling pathways [215]. The high (38 g/ kg) and medium $(19 \mathrm{~g} / \mathrm{kg})$ doses of QWBD showed significantly potent anti-inflammatory effects and reduced the pulmonary edema caused by ALuI in rats $(p<0.05)$. HPLC-DAD-ESI-MS ${ }^{n}$ combined with PCA indicated that verbascoside and angoroside C could reduce pulmonary edema. In addition, five compounds (i.e., galloylpaeoniflorin, pentagalloylglucose, mudanpioside C, ethyl gallate, and harpagoside) reduced the total cells of activated polymorphonuclear leukocytes and their infiltration for the treatment of ALuI [216]. Pharmacokinetic studies of QWBD are scarce. The chemical structures of some representative QWBD compounds are shown in Figure 1, and their potential action target pathways are summarized in Table 1.

\subsubsection{Xuanbai Chengqi Decoction}

The Xuanbai Chengqi decoction (XBCQ), first recorded in Wen Bing Tiao Bian, consists of Rheum palmatum rhizome and root (Dahuang), Gypsum Fibrosum (Shigao), Prunus armeniaca seed (Kuxingren), and Trichosanthes kirilowii fruit (Gualou). XBCQ "improved static/dynamic lung compliance" but also "reduced the complication incidence in patients with ARDS" [217]. XBCQ is also the basic formulation for Qifen syndrome in COVID19 [218]; in the critical stage, XBCQ is considered to reduce phlegm and clear heat [219]. A meta-analysis involving 11 RCTs and 992 participants indicated that XBCQ combined with Western medicine provided a better benefit than Western medicine alone to patients with severe pneumonia with the symptom pattern of phlegm-heat obstructing lungs in terms of the total effective rate $(\mathrm{RR}=1.23 ; 95 \% \mathrm{CI}(1.16,1.30))$, clinical pulmonary infection score (CPIS; $\mathrm{MD}=-2.02 ; 95 \% \mathrm{CI}(-2.42,-1.63))$, APACHE II (MD $=-6.81 ; 95 \% \mathrm{CI}(-8.26,5.37))$, mechanical ventilation time $(\mathrm{MD}=-101.41 ; 95 \% \mathrm{CI}(-140.47,-62.34))$, and lactic acid content in arterial blood $(\mathrm{MD}=-2.41 ; 95 \% \mathrm{CI}(-2.64,-2.18))$ [220]. For patients meeting the ARDS diagnostic criteria, the static lung compliance and dynamic lung compliance in the treatment group (adding XBCQ to conventional treatment), at 48 and $72 \mathrm{~h}$ after treatment, were significantly higher than in the control group (conventional treatment), and the plateau pressure, peak airway pressure, and positive end-expiratory pressure (PEEP) were significantly lower than before treatment [217].

In recent years, a growing body of evidence is showing that gut microbiota dysbiosis and overwhelming inflammation play an essential role in cell dysfunction and organ failure [221,222]. Gut microbiota dysbiosis can alter the dominant bacterial genera Clostridia and Enterococcaceae [223], and result in the loss of vital bacterial genera that produce shortchain fatty acids in healthy human beings, such as Prevotella and Ruminococcaceae [224]. At the initial hyper-inflammatory stage of sepsis, accompanied by alterations in the struc- 
tural and functional stability of gut integrity, bacteria and their products translocate via the mesenteric lymph node or portal venous blood and finally cause SIRS, ARDS, and MODS [222,225]. Dickson et al. discovered that the lung microbiome in patients with ARDS and sepsis was enriched with enteral bacteria. They also revealed a shared mechanism of pathogenesis on the basis of the close association between the relative abundance of enteral Bacteroides spp. and the serum level of TNF-á in patients with lethal diseases [226]. In a study by Mu et al., XBCQ exhibited protective effects in CLP rats by modulating the gut microbiota, restoring the gut barrier, and downregulating inflammatory responses [227]. Based on a network pharmacology study, the regulation by XBCQ of the PI3K/mTOR/HIF$1 \alpha /$ VEGF signaling pathway was proposed to be a crucial mechanism of the protective effect of XBCQ in the treatment of ALuI [228].

Phytochemistry studies of XBCQ are limited, although the chemical compositions of the component herbs Dahuang [229], Kuxingren [230], and Gualou [231] and the mineral medicine Shigao $\left(\mathrm{CaSO}_{4} \cdot 2 \mathrm{H}_{2} \mathrm{O}\right)$ have been widely investigated and defined. Pharmacokinetic studies of XBCQ are also limited. Emodin (originating from Dahuang; Figure 1) is the major constituent of XBCQ, and its potential target pathways are listed in Table 1 . The potential mechanism of antisepsis actions of the five CHM based on pathophysiologic processes involved in sepsis is shown in Figure 2.

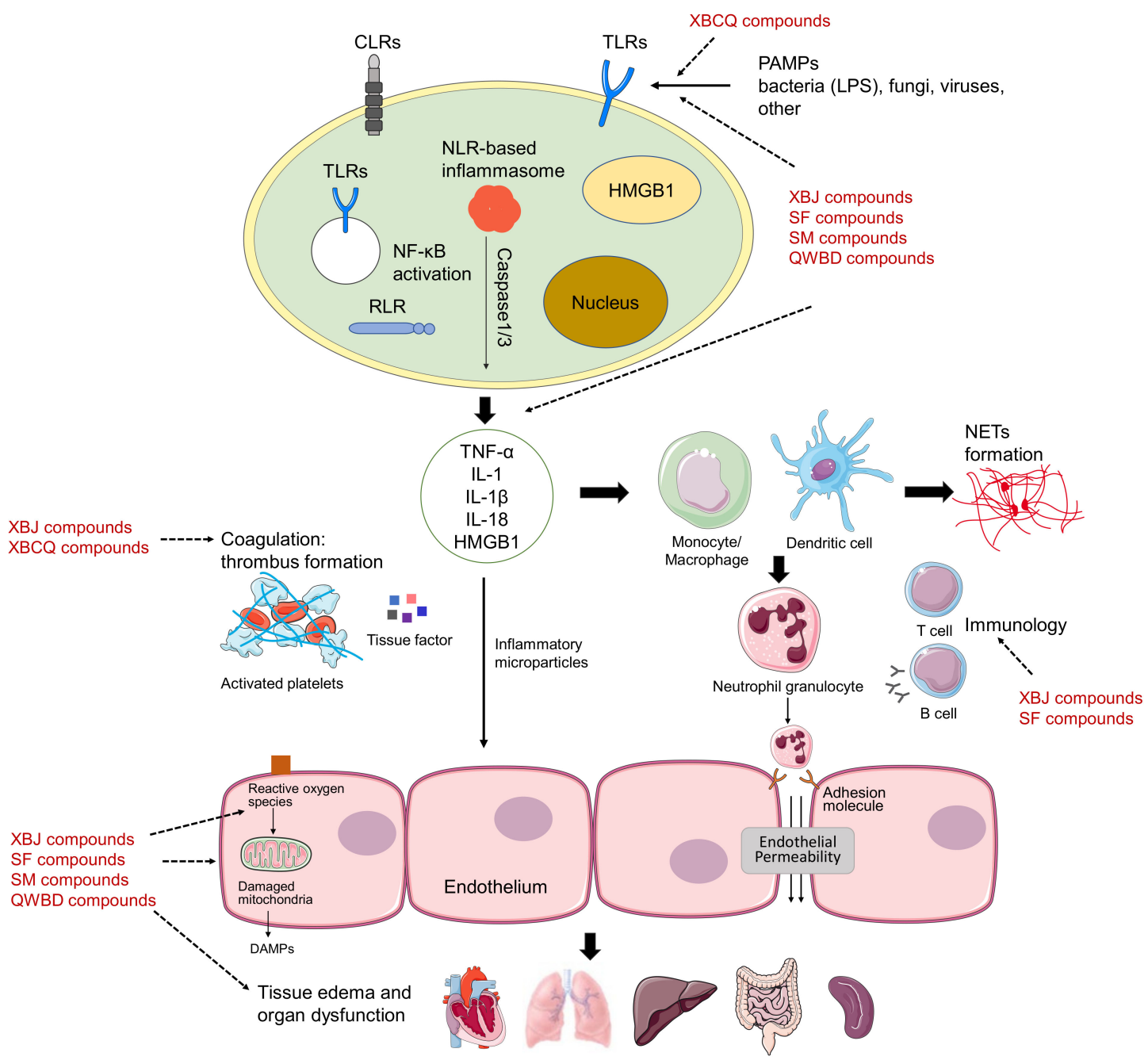

Figure 2. Potential mechanism of antisepsis actions of the five CHM based on pathophysiologic processes involved in sepsis. The dash line arrows indicate proposed action targets or signaling pathways that the five CHM probably involve; the solid 
line arrows indicate cascade mechanism of pathophysiology in sepsis. CLRs, C-type lectin receptors; TLRs, toll-like receptors; NLR, nucleotide binding domain and leucine-rich-repeat-containing proteins; RLR, Retinoic acid-inducible genelike receptors; HMGB1, high mobility group B-1; PAMPs, pathogen-associated molecular patterns; LPS, lipopolysaccharide; TNF- $\alpha$, tumor necrosis factor- $\alpha$; IL-1, interleukin 1 ; IL-1 $\beta$, interleukin $1 \beta$; IL-18, interleukin 18; DAMPs, damage-associated molecular-pattern molecules.

\subsection{Other Herbal Medicines}

Xing et al. summarized TCM combination therapies to treat septic acute gastrointestinal injury patients [232]. Compared with the control group, the 28-day mortality and gastrointestinal injury in the TCM-intervention group were significantly reduced $(p<0.05)$, as were the durations of mechanical ventilation and ICU stays $(p<0.05)$. Wang et al. found that the Sini decoction could restore microbial richness and abundance, reestablish the balance of intestinal flora, and thus ameliorate sepsis-related symptoms and pathology in CLP mice [233]. The Sini decoction was also found to ameliorate adrenal stress responses by downregulating TLR4 expression in adrenal tissue, demonstrating its promise for the prevention of adrenal insufficiency in prolonged sepsis [234]. The Fangji Fuling decoction inhibited the inflammatory and apoptotic response and further alleviated LPS-induced acute kidney injury [235]. The Xuefu Zhuyu decoction protected the myocardium in sepsis rats by the inhibition of myocardial cell apoptosis and antioxidation [236], whereas Shengjiang powder produced the same myocardium-protective effect by the downregulation of p38 MAPK phosphorylation [237]. The Xijiao Dihuang decoction was able to improve survival in sepsis via the regulation of the NF- $\mathrm{kB}$ and hypoxia-inducible factor- $1 \alpha$ signaling pathways [238].

\section{Discussion and Conclusions}

TCM plays an important and distinctive role in the treatment of sepsis in China, especially in the fight against COVID-19. More and more basic scientific research with regard to the pharmacological action, phytochemistry, and pharmacokinetics of TCM is being conducted. Nevertheless, the modernization of TCM still requires considerable work. The clinical efficacy of antisepsis CHM has been partly proven by well-designed and effectively executed clinical trials, meta-analyses aggregating the results of several similarly designed trials, and/or recommendations by authoritative treatment guidelines and expert consensuses. More multicenter, randomized, double-blind, placebo-controlled trials are needed to provide more evidence of clinical efficacy. The physiological and biochemical effects relevant to the antisepsis action of herbal medicines (as well as their component herbs or herbal compounds) have also been widely investigated via animal and/or cellular studies. However, studies extrapolating in vitro to in vivo and the translation of the antisepsis-related pharmacological properties from the laboratory to the clinic are insufficient. Thus, the material bases of most antisepsis CHM and the mechanisms of pharmacological actions have not yet been fully elucidated.

Phytochemistry studies of CHM provide the foundation of pharmacokinetic and pharmacology studies, based on which bioavailable and bioactive herbal compounds are identified, providing the foundation for developing potential drugs derived from CHM. Due to their complexity, the chemical composition analysis of herbal medicines normally requires advanced analytical technology and rich knowledge of phytochemistry. The chemical compositions of some antisepsis herbal injections have already been well defined, but for herbal prescriptions with more complex constituents, especially formulas containing several or more than ten component herbs, their definition is more difficult, and much more research needs to be conducted.

In recent years, the underlying mechanisms of action of antisepsis CHM have been tentatively explored using network pharmacology and molecular docking analysis. Several network pharmacology methods for TCM studies have been developed, mainly to predict the pharmacological actions of herbal compounds and their targets, as well as to screen synergistic multiple compounds from herbal formulas [239]. Bioactive compounds 
could be discovered and the mechanisms of action of herbal formulas could be tentatively elucidated using network-based methods. However, network pharmacology has its own limitations: (1) it mainly focuses on unchanged compounds (prototype constituents) of herbal medicines rather than their real systemic exposure forms (unchanged and/or metabolized) after the administration of the medicines, and (2) it normally does not incorporate the fluctuation in compounds' concentrations (systemic exposure levels) over time or the compounds' reachability in vivo after dosing the medicines. In terms of these two points, pharmacokinetics could act as a powerful complement to network pharmacology studies and provide important information for traditional pharmacology studies.

Pharmacokinetics plays an important role in clarifying the material basis of CHM. Based on comprehensive composition analysis of antisepsis CHM, pharmacokinetics is used to identify herbal compounds with high systemic exposure (bioavailable com pounds) for further antisepsis-related pharmacological studies (i.e., pharmacokinetics provides bioavailable compounds and concentrations). However, pharmacokinetic studies of these antisepsis CHM have been in their infancy for a long time, which is mainly attributed to the limitations of analytical techniques and pharmacokinetic knowledge. In just under a decade, the pharmacokinetic studies of CHM have rapidly developed $[92,93,240,241]$ and the pharmacokinetic studies of XBJ provide a successful example of this [29,49-51]. Pharmacokinetic studies have suggested that the material-basis studies of herbal medicines should not only be concerned with the unchanged compounds (prototypes) but also the metabolites. Accordingly, antisepsis-related pharmacological studies, focusing mainly on the significantly bioavailable herbal compounds (in unchanged and/or metabolized forms), facilitate revealing the material bases of antisepsis herbal medicines.

The destruction of the intestinal microbiota is a risk factor for sepsis. In sepsis, the compositions of the intestinal microbiomes of patients are severely affected, which might lead to the development of organ failure. Therefore, the modulation of the gut microbiota and the improvement of intestinal barrier function are expected to be important for the prognosis of sepsis patients [227]. CHMs have been demonstrated to restore microbiota homeostasis, improve intestinal and lung epithelium proliferation, improve intestinal barrier integrity, and suppress hyperimmune reactions [227]. Some types of herbal medicines can regulate the composition and metabolism of the intestinal flora, thereby improving the body's dysfunction and pathological conditions; for instance, glycosides, flavonoids, alkaloids, phenylpropanoids, and organic acids are known to affect the intestinal flora. The intestinal florae participate in the metabolic transformation of herbs but also transform herbal compounds to improve bioavailability. Flavonoids have certain regulatory effects on the intestinal flora and can be catabolized by microorganisms, causing changes in their bioavailability and activity. Therefore, understanding the roles in regulating intestinal florae is important for clarifying the mechanisms of action of antisepsis herbal medicines.

Based on the current studies of the antisepsis CHMs, many bioactive herbal compounds belonging to the flavonoids, monoterpene glycosides, catechols, phthalides, ginsenosides, steroidal saponins, etc., have been identified as possessing antisepsis-related pharmacological activities and showing significant systemic exposure for exhibiting bioactivities after the administration of medicines. In the future, the elucidation of the material basis of antisepsis CHMs will require joint multidisciplinary efforts to provide an important basis for clarifying the pathogenesis of sepsis and developing novel antisepsis drugs.

Author Contributions: Conceptualization, C.C.; writing-original draft preparation, writingreview and editing, C.C. and X.Y.; funding acquisition, C.C. All authors have read and agreed to the published version of the manuscript.

Funding: This work was funded by grants from the National Natural Science Foundation of China (82074176).

Institutional Review Board Statement: Not applicable.

Informed Consent Statement: Not applicable. 
Data Availability Statement: Not applicable.

Conflicts of Interest: The authors declare no conflict of interest.

\section{Abbreviations}

\begin{tabular}{|c|c|}
\hline ADE & Adverse drug event \\
\hline ADR & Adverse drug reaction \\
\hline ALuI & Acute lung injury \\
\hline ALT & Alanine aminotransferase \\
\hline AMP & Adenosine 5'-monophosphate \\
\hline APACHE II & Acute Physiology and Chronic Health Evaluation II \\
\hline ARDS & Acute respiratory distress syndrome \\
\hline AST & Aspartate aminotransferase \\
\hline BUN & Blood urea nitrogen \\
\hline$C_{\max }$ & Maximum plasma concentrations \\
\hline COVID-19 & Coronavirus disease 2019 \\
\hline $\mathrm{CHM}$ & Chinese herbal medicines \\
\hline CLP & Cecal ligation and puncture \\
\hline $\mathrm{Cr}$ & Creatinine \\
\hline HLA-DR & Human leukocyte antigen-DR \\
\hline ICU & Intensive care unit \\
\hline $\mathrm{LDH}$ & Lactate dehydrogenase \\
\hline IFN- $\gamma$ & Interferon- $\gamma$ \\
\hline IL-6 & Interleukin 6 \\
\hline LPS & Lipopolysaccharide \\
\hline MAP & Mean arterial pressure \\
\hline MLC & Myosin light chain \\
\hline MLCK & Myosin light-chain kinase \\
\hline MMP-2/9 & Matrix metalloproteinase 2/9 \\
\hline MODS & Multiple organ dysfunction syndrome \\
\hline $\mathrm{OGD} / \mathrm{R}$ & Oxygen-glucose deprivation/reoxygenation \\
\hline PEEP & Positive end-expiratory pressure \\
\hline PSCC & Preventing Sepsis Campaign in China \\
\hline QWBD & Qingwen Baidu decoction \\
\hline ROCK & Rho-associated coil-forming protein kinase \\
\hline SCCM & Society of Critical Care Medicine \\
\hline SIRS & Systemic inflammatory response syndrome \\
\hline 20(S)-protopanaxadiol type & ppd-type \\
\hline 20(S)-protopanaxatriol type & ppt-type \\
\hline SF & ShenFu injection \\
\hline SM & ShengMai \\
\hline SOCS1 & Suppressor of cytokine signaling 1 \\
\hline SOFA & Sequential Organ Failure Assessment \\
\hline SIRS & Systemic inflammatory response syndrome \\
\hline$t_{1 / 2}$ & Half-life \\
\hline TCM & Traditional Chinese medicine \\
\hline TNF- $\alpha$ & Tumor necrosis factor- $\alpha$ \\
\hline XBCQ & Xuanbai Chengqi decoction \\
\hline XBJ & XueBiJing injection \\
\hline
\end{tabular}

\section{References}

1. Singer, M.; Deutschman, C.S.; Seymour, C.C.; Shankar-Hari, M.; Annane, D.; Bauer, M.; Bellomo, R.; Bernard, G.R.; Chiche, J.-D.; Coopersmith, C.C.M.; et al. The Third International Consensus Definitions for Sepsis and Septic Shock (Sepsis-3). JAMA 2016, 315, 801-810. [CrossRef] [PubMed]

2. Fleischmann, M.C.; Scherag, A.; Adhikari, N.K.J.; Hartog, C.S.; Tsaganos, T.; Schlattmann, P.; Angus, D.C.; Reinhart, K.; on behalf of the International Forum Acute Care Trialists. Assessment of Global Incidence and Mortality of Hospital-treated Sepsis. Am. J. Respir. Crit. Care Med. 2016, 193, 259-272. [CrossRef] [PubMed] 
3. Xie, J.; Wang, H.; Kang, Y.; Zhou, L.; Liu, Z.; Qin, B.; Ma, X.; Cao, X.; Chen, D.; Lu, W.; et al. The Epidemiology of Sepsis in Chinese ICUs. Crit. Care Med. 2020, 48, e209-e218. [CrossRef]

4. Phelan, A.L.; Katz, R.; Gostin, L.O. The Novel Coronavirus Originating in Wuhan, China Challenges for Global Health Governance. JAMA 2020, 323, 709. [CrossRef] [PubMed]

5. Fan, T.-T.; Cheng, B.-L.; Fang, X.-M.; Chen, Y.-C.; Su, F. Application of Chinese Medicine in the Management of Critical Conditions: A Review on Sepsis. Am. J. Chin. Med. 2020, 48, 1315-1330. [CrossRef] [PubMed]

6. Hotchkiss, R.R.; Moldawer, L.L.L.; Opal, S.M.; Reinhart, K.; Turnbull, I.I.; Vincent, J.-L. Sepsis and septic shock. Nat. Rev. Dis. Prim. 2016, 2, 1-21. [CrossRef]

7. Gotts, J.E.; Matthay, M.A. Sepsis: Pathophysiology and clinical management. BMJ 2016, 353, i1585. [CrossRef] [PubMed]

8. Bone, R.C.; Balk, R.A.; Cerra, F.B.; Dellinger, R.P.; Fein, A.M.; Knaus, W.A.; Schein, R.M.H.; Sibbald, W.J. Definitions for Sepsis And Organ Failure and Guidelines for the Use of Innovative Therapies in Sepsis. Chest 1992, 101, 1644-1655. [CrossRef]

9. Levy, M.M.; Fink, M.P.; Marshall, J.C.; Abraham, E.; Angus, D.; Cook, D.; Cohen, J.; Opal, S.M.; Vincent, J.L.; Ramsay, G. 2001 SCCM/ESICM/ACCP/ATS/SIS International Sepsis Definitions Conference. Crit. Care Med. 2003, 31, 1250-1256. [CrossRef] [PubMed]

10. Van Der Poll, T.; Van De Veerdonk, F.L.; Scicluna, B.; Netea, M.G. The immunopathology of sepsis and potential therapeutic targets. Nat. Rev. Immunol. 2017, 17, 407-420. [CrossRef]

11. Angus, D.C.; Van Der Poll, T. Severe Sepsis and Septic Shock. Neww Engl. J. Med. 2013, 369, 840-851. [CrossRef]

12. Rhodes, A.; Evans, L.E.; Alhazzani, W.; Levy, M.M.; Antonelli, M.; Ferrer, R.; Kumar, A.; Sevransky, J.E.; Sprung, C.L.; Nunnally, M.E.; et al. Surviving Sepsis Campaign: International Guidelines for Management of Sepsis and Septic Shock: 2016. Crit. Care Med. 2017, 45, 486-552. [CrossRef] [PubMed]

13. Cecconi, M.; Evans, L.; Levy, M.; Rhodes, A. Sepsis and septic shock. Lancet 2018, 392, 75-87. [CrossRef]

14. Cohen, J.; Vincent, J.-L.; Adhikari, N.K.J.; Machado, F.R.; Angus, D.C.; Calandra, T.; Jaton, K.; Giulieri, S.; Delaloye, J.; Opal, S.; et al. Sepsis: A roadmap for future research. Lancet Infect. Dis. 2015, 15, 581-614. [CrossRef]

15. Wang, Z.; Yu, X.; Chen, Y.; Lv, C.; Zhao, X. Chinese expert consensus on early prevention and intervention of sepsis. Asian Pac. J. Trop. Med. 2020, 13, 335-349. [CrossRef]

16. Zhao, G.-Z.; Chen, R.-B.; Li, B.; Guo, Y.-H.; Xie, Y.-M.; Liao, X.; Yang, Y.-F.; Chen, T.-F.; Di, H.-R.; Shao, F.; et al. Clinical practice guideline on traditional Chinese medicine therapy alone or combined with antibiotics for sepsis. Ann. Transl. Med. 2018, 43, 4776-4881. [CrossRef]

17. Yu, X.-Z.; Yao, Y.-M.; Zhou, R.-B. Chinese Guidelines for Emergency Management of Sepsis and Septic Shock 2018. J. Clin. Emerg. 2018, 38, 741-756. [CrossRef]

18. Wang, L.-J.; Chia, Y.-F. Chinese Emergency Medicine Expert Consensus on Diagnosis and Treatment of Sepsis Complicated with Disseminated Intravascular Coagulation. Chin. Crit. Care Med. 2017, 29, 577-580. [CrossRef]

19. Chinese National Health Commission and Chinese State Administration of Traditional Chinese Medicine. Diagnosis and Treatment of Adults with Coronavirus Disease 2019 (COVID-19) (The Revised Eighth Version). 2021. Available online: http:/ / www.gov.cn/zhengce/zhengceku/2021-04/15/5599795/files/e9ce837932e6434db998bdbbc5d36d32.pdf (accessed on 28 August 2021).

20. Li, C.; Wang, P.; Zhang, L.; Li, M.; Lei, X.; Liu, S.; Feng, Z.; Yao, Y.; Chang, B.; Liu, B.; et al. Efficacy and safety of Xuebijing injection (a Chinese patent) for sepsis: A meta-analysis of randomized controlled trials. J. Ethnopharmacol. 2018, 224, 512-521. [CrossRef]

21. Chen, G.; Gao, Y.; Jiang, Y.; Yang, F.; Li, S.; Tan, D.; Ma, Q. Efficacy and Safety of Xuebijing Injection Combined with Ulinastatin as Adjunctive Therapy on Sepsis: A Systematic Review and Meta-Analysis. Front. Pharmacol. 2018, 9, 743. [CrossRef]

22. Gao, J.; Kong, L.; Liu, S.; Feng, Z.; Shen, H.; Liu, Q. A prospective multicenter clinical study of Xuebijing injection in the treatment of sepsis and multiple organ dysfunction syndrome. Chin. Crit. Care Med. 2015, 27, 465-470. [CrossRef]

23. Chen, Y.-X.; Li, C.-S. The Effectiveness of XueBiJing Injection in Therapy of Sepsis: A Multicenter Clinical Study. China J. Emerg. Med. 2013, 22, 130-135. [CrossRef]

24. Wu, Y.; Zhang, J.; Qi, L. Clinical efficacy and safety of Xuebijing injection on sepsis: A Meta-analysis. Chin. Crit. Care Med. 2020, 32, 691-695. [CrossRef]

25. Song, Y.; Yao, C.; Yao, Y.; Han, H.; Zhao, X.; Yu, K.; Liu, L.; Xu, Y.; Liu, Z.; Zhou, Q.; et al. XueBijing Injection Versus Placebo for Critically Ill Patients with Severe Community-Acquired Pneumonia. Crit. Care Med. 2019, 47, e735-e743. [CrossRef]

26. Luo, Z.; Chen, W.; Xiang, M.; Wang, H.; Xiao, W.; Xu, C.; Li, Y.; Min, J.; Tu, Q. The preventive effect of Xuebijing injection against cytokine storm for severe patients with COVID-19: A prospective randomized controlled trial. Eur. J. Integr. Med. 2021, $42,101305$. [CrossRef] [PubMed]

27. Zheng, R.; Wang, H.; Liu, Z.; Wang, X.; Li, J.; Lei, X.; Fan, Y.; Liu, S.; Feng, Z.; Shang, H. A real-world study on adverse drug reactions to Xuebijing injection: Hospital intensive monitoring based on 93 hospitals (31,913 cases). Ann. Transl. Med. 2019, 7, 117. [CrossRef]

28. Wang, C.; Shi, Q.-P.; Ding, F.; Jiang, X.-D.; Tang, W.; Yu, M.-L.; Cheng, J.-Q. Reevaluation of the post-marketing safety of Xuebijing injection based on real-world and evidence-based evaluations. Biomed. Pharmacother. 2019, 109, 1523-1531. [CrossRef] 
29. Li, J.; Olaleye, O.E.; Yu, X.; Jia, W.; Yang, J.; Lu, C.; Liu, S.; Yu, J.; Duan, X.; Wang, Y.; et al. High degree of pharmacokinetic compatibility exists between the five-herb medicine XueBijing and antibiotics comedicated in sepsis care. Acta Pharm. Sin. B 2019, 9, 1035-1049. [CrossRef] [PubMed]

30. Zuo, L.; Zhou, L.; Xu, T.; Li, Z.; Liu, L.; Shi, Y.; Kang, J.; Gao, G.; Du, S.; Sun, Z.; et al. Antiseptic Activity of Ethnomedicinal Xuebijing Revealed by the Metabolomics Analysis Using UHPLC-Q-Orbitrap HRMS. Front. Pharmacol. 2018, 9, 300. [CrossRef]

31. Xu, T.; Zhou, L.; Shi, Y.; Liu, L.; Zuo, L.; Jia, Q.; Du, S.; Kang, J.; Zhang, X.; Sun, Z. Metabolomics approach in lung tissue of septic rats and the interventional effects of Xuebijing injection using UHPLC-Q-Orbitrap-HRMS. J. Biochem. 2018, 164, 427-435. [CrossRef] [PubMed]

32. Chen, X.; Feng, Y.; Shen, X.; Pan, G.; Fan, G.; Gao, X.; Han, J.; Zhu, Y. Anti-sepsis protection of Xuebijing injection is mediated by differential regulation of pro- and anti-inflammatory Th17 and T regulatory cells in a murine model of polymicrobial sepsis. J. Ethnopharmacol. 2018, 211, 358-365. [CrossRef] [PubMed]

33. Jiang, M.; Zhou, M.; Han, Y.; Xing, L.; Zhao, H.; Dong, L.; Bai, G.; Luo, G. Identification of NF-kB Inhibitors in Xuebijing injection for sepsis treatment based on bioactivity-integrated UPLC-Q/TOF. J. Ethnopharmacol. 2013, 147, 426-433. [CrossRef]

34. Zhou, W.; Lai, X.; Wang, X.; Yao, X.; Wang, W.; Li, S. Network pharmacology to explore the anti-inflammatory mechanism of Xuebijing in the treatment of sepsis. Phytomedicine 2021, 85, 153543. [CrossRef]

35. Li, A.; Li, J.; Bao, Y.; Yuan, D.; Huang, Z. Xuebijing injection alleviates cytokine-induced inflammatory liver injury in CLP-induced septic rats through induction of suppressor of cytokine signaling 1. Exp. Ther. Med. 2016, 12, 1531-1536. [CrossRef]

36. Li, T.; Qian, Y.; Miao, Z.; Zheng, P.; Shi, T.; Jiang, X.; Pan, L.; Qian, F.; Yang, G.; An, H.; et al. Xuebijing Injection Alleviates Pam3CSK4-Induced Inflammatory Response and Protects Mice from Sepsis Caused by Methicillin-Resistant Staphylococcus aureus. Front. Pharmacol. 2020, 11, 104. [CrossRef] [PubMed]

37. Liu, J.; Wang, Z.; Lin, J.; Li, T.; Guo, X.; Pang, R.; Dong, L.; Duan, M. Xuebijing injection in septic rats mitigates kidney injury, reduces cortical microcirculatory disorders, and suppresses activation of local inflammation. J. Ethnopharmacol. 2021, 276, 114199. [CrossRef]

38. Geng, P.; Zhang, H.; Xiong, J.; Wang, Y.; Ling, B.; Wang, H.; Tan, D.; Wang, D.; Zhang, J. XueBiJing Injection Attenuates Hydrogen Sulfide-induced Endothelial Barrier Dysfunction by Upregulating Claudin-5 Expression. Chin. Crit. Care Med. 2020, 32, 443-448. [CrossRef]

39. Jiang, Y.; Zou, L.; Liu, S.; Liu, X.; Chen, F.; Liu, X.; Zhu, Y. GC/MS-based metabonomics approach reveals effects of Xuebijing injection in CLP induced septic rats. Biomed. Pharmacother. 2019, 117, 109163. [CrossRef]

40. Tianyu, Z.; Liying, G. Identifying the molecular targets and mechanisms of xuebijing injection for the treatment of COVID-19 via network parmacology and molecular docking. Bioengineered 2021, 12, 2274-2287. [CrossRef]

41. Zhang, B.; Zhang, D.; Lv, J.-T.; Sa, R.-N.; Ma, B.-B.; Zhang, X.-M.; Lin, Z.-J. Molecular insight into the therapeutic promise of xuebijing injection against coronavirus disease 2019. World J. Tradit. Chin. Med. 2020, 6, 203-215. [CrossRef]

42. Zuo, L.-H.; Zhou, L.; Shi, Y.-Y.; Li, Z.-L.; Liu, L.-W.; Jiang, X.-F.; Wang, D.; Yan, S.-X.; Sun, Z.; Zhang, X.-J. Mechanism of XueBijing Injection in Anti-acute Lung Injury Based on Network Pharmacology. Chin. Tradit. Herb. Drugs 2018, 49, 3541-3549.

43. Feng, Y.-Y.; Xie, Y.-Y.; Wang, Y.-P.; Lian, Q.; Wang, Y.-M.; Luo, G.-A.; Wang, S.-M. Molecular Mechanism of XueBiJing Injection in Treatment of Sepsis according to Drug-target-pathway Network. Acta Pharmaceut Sin. 2017, 52, 556-562.

44. Sun, Z.; Zuo, L.; Sun, T.; Tang, J.; Ding, D.; Zhou, L.; Kang, J.; Zhang, X. Chemical profiling and quantification of XueBiJing injection, a systematic quality control strategy using UHPLC-Q Exactive hybrid quadrupole-orbitrap high-resolution mass spectrometry. Sci. Rep. 2017, 7, 1-15. [CrossRef] [PubMed]

45. Li, D.; Cao, X.-X.; Pu, W.-L.; Sun, L.-L.; Ren, X.-L. Research on Quality Control Method of XueBiJing Injection. Mod. Chin. Med. 2018, 20, 1157-1160. [CrossRef]

46. Zuo, L.; Sun, Z.; Hu, Y.; Sun, Y.; Xue, W.; Zhou, L.; Zhang, J.; Bao, X.; Zhu, Z.; Suo, G.; et al. Rapid determination of 30 bioactive constituents in XueBijing injection using ultra high performance liquid chromatography-high resolution hybrid quadrupole-orbitrap mass spectrometry coupled with principal component analysis. J. Pharm. Biomed. Anal. 2017, 137, 220-228. [CrossRef]

47. Huang, H.; Wang, J.; Fu, J.Z.; Wang, L.Q.; Zhao, H.Z.; Song, S.Y.; Ji, L.X.; Jiang, M.; Bai, G.; Luo, G.A. Simultaneous determination of thirteen main components and identification of eight major metabolites in Xuebijing Injection by UPLC/Q-TOF. J. Anal. Chem. 2013, 68, 348-356. [CrossRef]

48. Chen, Y.; Li, Y.; Chen, X.; Wang, L.; Sun, C.; Yan, W.; Liu, X. Development and Validation of a HPLC Method for the Determination of Five Bioactive Compounds in the "Xuebijing" Injection. Anal. Lett. 2010, 43, 2456-2464. [CrossRef]

49. Zhang, N.; Cheng, C.; Olaleye, O.E.; Sun, Y.; Li, L.; Huang, Y.; Du, F.; Yang, J.; Wang, F.; Shi, Y.; et al. Pharmacokinetics-Based Identification of Potential Therapeutic Phthalides from XueBiJing, a Chinese Herbal Injection Used in Sepsis Management. Drug Metab. Dispos. 2018, 46, 823-834. [CrossRef]

50. Li, X.; Cheng, C.; Wang, F.; Huang, Y.; Jia, W.; Olaleye, O.; Li, M.; Li, Y.; Li, C. Pharmacokinetics of catechols in human subjects intravenously receiving XueBijing injection, an emerging antiseptic herbal medicine. Drug Metab. Pharmacokinet. 2016, 31, 95-98. [CrossRef]

51. Cheng, C.; Lin, J.-Z.; Li, L.; Yang, J.-L.; Jia, W.-W.; Huang, Y.-H.; Du, F.-F.; Wang, F.-Q.; Li, M.-J.; Li, Y.-F.; et al. Pharmacokinetics and disposition of monoterpene glycosides derived from Paeonia lactiflora roots (Chishao) after intravenous dosing of antiseptic XueBiJing injection in human subjects and rats. Acta Pharmacol. Sin. 2016, 37, 530-544. [CrossRef] [PubMed] 
52. Zuo, L.; Sun, Z.; Wang, Z.; Ding, D.; Xu, T.; Liu, L.; Gao, L.; Du, S.; Kang, J.; Zhang, X. Tissue distribution profiles of multiple major bioactive components in rats after intravenous administration of Xuebijing injection by UHPLC-Q-Orbitrap HRMS. Biomed. Chromatogr. 2019, 33, e4400. [CrossRef]

53. Ouyang, H.-Z.; He, J. Simultaneous determination of nine constituents of Xuebijing Injection in rat plasma and their pharmacokinetics by LC-MS/MS. China J. Chin. Mater. Med. 2018, 43, 3553-3561. [CrossRef]

54. Zuo, L.; Zhong, Q.; Wang, Z.; Sun, Z.; Zhou, L.; Li, Z.; Xu, T.; Shi, Y.; Tang, J.; Du, S.; et al. Simultaneous determination and pharmacokinetic study of twelve bioactive compounds in rat plasma after intravenous administration of Xuebijing injection by UHPLC-Q-Orbitrap HRMS. J. Pharm. Biomed. Anal. 2017, 146, 347-353. [CrossRef] [PubMed]

55. Chen, X.-M.; Wang, X.-W.; Luo, J.; Jia, P.; Wang, X.-Y.; Xiao, C.-N.; Wang, S.-X.; Liu, Q.-S.; Zheng, X.-H. Pharmacokinetic Studies of XueBiJing Injection in Rats. Chin. J. Pharm. Anal. 2012, 32, 744-748. [CrossRef]

56. Sheng, C.; Peng, W.; Xia, Z.; Wang, Y. Plasma and cerebrospinal fluid pharmacokinetics of hydroxysafflor yellow A in patients with traumatic brain injury after intravenous administration of Xuebijing using LC-MS/MS method. Xenobiotica 2019, 50, 545-551. [CrossRef] [PubMed]

57. Wang, Y.; Che, J.; Zhao, H.; Tang, J.; Shi, G. Paeoniflorin attenuates oxidized low-density lipoprotein-induced apoptosis and adhesion molecule expression by autophagy enhancement in human umbilical vein endothelial cells. J. Cell. Biochem. 2019, 120, 9291-9299. [CrossRef] [PubMed]

58. Xu, J.; Yang, L.; Dong, L. Tanshinol upregulates the expression of aquaporin 5 in lung tissue of rats with sepsis. Oncol. Lett. 2018, 16, 3290-3296. [CrossRef]

59. Sun, Y.; Xu, D.-P.; Qin, Z.; Wang, P.-Y.; Hu, B.-H.; Yu, J.-G.; Zhao, Y.; Cai, B.; Chen, Y.-L.; Lu, M.; et al. Protective cerebrovascular effects of hydroxysafflor yellow A (HSYA) on ischemic stroke. Eur. J. Pharmacol. 2018, 818, 604-609. [CrossRef]

60. Ji, L.; Hou, X.; Liu, W.; Deng, X.; Jiang, Z.; Huang, K.; Li, R. Paeoniflorin inhibits activation of the IRAK1-NF- $\mathrm{B}$ signaling pathway in peritoneal macrophages from lupus-prone MRL/lpr mice. Microb. Pathog. 2018, 124, 223-229. [CrossRef]

61. Bai, J.; Zhao, J.; Cui, D.; Wang, F.; Song, Y.; Cheng, L.; Gao, K.; Wang, J.; Li, L.; Li, S.; et al. Protective effect of hydroxysafflor yellow A against acute kidney injury via the TLR4/NF-kB signaling pathway. Sci. Rep. 2018, 8, 1-11. [CrossRef]

62. Xu, X.; Guo, Y.; Zhao, J.; Wang, N.; Ding, J.; Liu, Q. Hydroxysafflor Yellow A Inhibits LPS-Induced NLRP3 Inflammasome Activation via Binding to Xanthine Oxidase in Mouse RAW264.7 Macrophages. Mediat. Inflamm. 2016, 2016, 1-11. [CrossRef] [PubMed]

63. Wang, L.; Liu, Z.; Dong, Z.; Pan, J.; Ma, X. Effects of Xuebijing injection on microcirculation in septic shock. J. Surg. Res. 2016, 202, 147-154. [CrossRef] [PubMed]

64. Hu, Y.; Duan, M.; Liang, S.; Wang, Y.; Feng, Y. Senkyunolide I protects rat brain against focal cerebral ischemia-reperfusion injury by up-regulating p-Erk1/2, Nrf2/HO-1 and inhibiting caspase 3. Brain Res. 2015, 1605, 39-48. [CrossRef]

65. Ji, X.-F.; Ji, H.-B.; Sang, D.-Y.; Wang, S.; Yang, L.; Li, C.-S. Shen-Fu Injection Reduces Impaired Myocardial Beta-adrenergic Receptor Signaling after Cardiopulmonary Resuscitation. Chin. Med. J. 2013, 126, 697-702. [CrossRef]

66. Chen, T.; Cheng, M.; Yuan, Z.; Zhou, S.; Yu, Z. Protective Role of Shenfu on Ischemia-Reperfusion Injury of Rat Liver Grafts. Transplant. Proc. 2012, 44, 978-981. [CrossRef] [PubMed]

67. Hong, F.; He, C.; Liu, X.; Tu, G.; Guo, F.; Yang, S. Protective effect of Shenfu injection on thromboangiitis obliterans model rats. J. Ethnopharmacol. 2011, 138, 458-462. [CrossRef]

68. Zhu, W.-H.; Leng, X.-S.; Zhu, J.-Y. Effect of Shenfu injection on ischemia-reperfusion injury of rat liver graft. Hepatobiliary Pancreat. Dis. Int. 2006, 5, 205-209. [PubMed]

69. Li, M.; Pan, T.; Lyu, L.; Zhang, W.; Tan, R.; Liu, Z.; Wang, X.; Li, L.; Liu, J.; Zheng, L.; et al. Effect of traditional Chinese medicine syndrome differentiation and standard bundle therapy in patients with septic shock. Chin. Crit. Care Med. 2019, 31, 852-856. [CrossRef]

70. Fan, K.-L.; Wang, J.-H.; Kong, L.; Zhang, F.-H.; Hao, H.; Tian, Z.-Y.; Yin, M.-X.; Fang, H.; Yang, H.-H.; Liu, Y. Effect of Shen-Fu Injection on Hemodynamics in Early Volume Resuscitation Treated Septic Shock Patients. Chin. J. Integr. Med. 2019, 25, 59-63. [CrossRef]

71. Mou, Z.; Lv, Z.; Li, Y.; Wang, M.; Xu, Q.; Yu, X. Clinical Effect of Shenfu Injection in Patients with Septic Shock: A Meta-Analysis and Systematic Review. Evid.-Based Complement. Altern. Med. 2015, 2015, 1-10. [CrossRef]

72. Huang, P.; Guozhen, Z.; Feng, S.; Zhao, G.; Li, B.; Liu, Q. Efficacy and safety of Shenfu injection for septic shock: A systematic review and meta-analysis of randomized controlled trials. Am. J. Emerg. Med. 2019, 37, 2197-2204. [CrossRef]

73. Li, Y.; Zhang, X.; Lin, P.; Qiu, H.; Wei, J.; Cao, Y.; Pan, S.; Walline, J.; Qian, C.; Shan, Z.; et al. Effects of Shenfu Injection in the Treatment of Septic Shock Patients: A Multicenter, Controlled, Randomized, Open-Label Trial. Evid.-Based Complement. Altern. Med. 2016, 2016, 1-9. [CrossRef]

74. Zhang, N.; Liu, J.; Qiu, Z.; Ye, Y.; Zhang, J.; Lou, T. Shenfu injection for improving cellular immunity and clinical outcome in patients with sepsis or septic shock. Am. J. Emerg. Med. 2017, 35, 1-6. [CrossRef]

75. Lv, S.J.; Lai, D.P.; Wei, X.; Yan, Q.; Xia, J.M. The protective effect of Shenfu injection against elderly severe pneumonia. Eur. J. Trauma Emerg. Surg. 2016, 43, 711-715. [CrossRef]

76. Jin, M.; Sun, C.-Y.; Zang, B.-X. Hydroxysafflor yellow A attenuate lipopolysaccharide-induced endothelium inflammatory injury. Chin. J. Integr. Med. 2015, 22, 36-41. [CrossRef] 
77. Wang, K.; Hu, W. Oxypaeoniflorin improves myocardial ischemia/reperfusion injury by activating the Sirt1/Foxo1 signaling pathway. Acta Biochim. Pol. 2020, 67, 239-245. [CrossRef]

78. Zhang, Q.; Zhou, J.; Huang, M.; Bi, L.; Zhou, S. Paeoniflorin Reduced BLP-Induced Inflammatory Response by Inhibiting the NF-kB Signal Transduction in Pathway THP-1 Cells. Cent. Eur. J. Immunol. 2014, 39, 461-467. [CrossRef] [PubMed]

79. Li, G.; Seo, C.-S.; Lee, K.-S.; Kim, H.-J.; Chang, H.-W.; Jung, J.-S.; Song, D.-K.; Son, J.-K. Protective constituents against sepsis in mice from the root cortex ofPaeonia suffruticosa. Arch. Pharmacal Res. 2004, 27, 1123-1126. [CrossRef]

80. Xie, J.; Zhao, Z.-Z.; Li, P.; Zhu, C.-L.; Guo, Y.; Wang, J.; Deng, X.-M.; Wang, J.-F. Senkyunolide I Protects against Sepsis-Associated Encephalopathy by Attenuating Sleep Deprivation in a Murine Model of Cecal Ligation and Puncture. Oxidative Med. Cell. Longev. 2021, 2021, 1-11. [CrossRef]

81. Su, F.; Xue, Y.; Wang, Y.; Zhang, L.; Chen, W.; Hu, S. Protective Effect of Ginsenosides Rg1 and Re on Lipopolysaccharide-Induced Sepsis by Competitive Binding to Toll-Like Receptor 4. Antimicrob. Agents Chemother. 2015, 59, 5654-5663. [CrossRef] [PubMed]

82. Lee, W.; Ku, S.-K.; Jeong, T.C.; Lee, S.; Bae, J.-S. Ginsenosides Inhibit HMGB1-induced Inflammatory Responses in HUVECs and in Murine Polymicrobial Sepsis. Bull. Korean Chem. Soc. 2014, 35, 2955-2962. [CrossRef]

83. Zou, Y.; Tao, T.; Tian, Y.; Zhu, J.; Cao, L.; Deng, X.; Li, J. Ginsenoside Rg1 improves survival in a murine model of polymicrobial sepsis by suppressing the inflammatory response and apoptosis of lymphocytes. J. Surg. Res. 2013, 183, 760-766. [CrossRef]

84. Zhang, L.; Zhu, M.; Li, M.; Du, Y.; Duan, S.; Huang, Y.; Lu, Y.; Zhang, J.; Wang, T.; Fu, F. Ginsenoside Rg1 attenuates adjuvantinduced arthritis in rats via modulation of PPAR- $\gamma / \mathrm{NF}-\kappa \mathrm{B}$ signal pathway. Oncotarget 2017, 8, 55384-55393. [CrossRef]

85. Huang, Q.; Wang, T.; Wang, H.-Y. Ginsenoside Rb2 enhances the anti-inflammatory effect of $\omega$-3 fatty acid in LPS-stimulated RAW264.7 macrophages by upregulating GPR120 expression. Acta Pharmacol. Sin. 2016, 38, 192-200. [CrossRef]

86. Zhang, J.; Cao, L.; Wang, H.; Cheng, X.; Wang, L.; Zhu, L.; Yan, T.; Xie, Y.; Wu, Y.; Zhao, M.; et al. Ginsenosides Regulate PXR/NF-кB Signaling and Attenuate Dextran Sulfate Sodium-Induced Colitis. Drug Metab. Dispos. 2015, 43, 1181-1189. [CrossRef]

87. Sun, R.-J.; Li, Y.-N.; Chen, W.; Zhang, F.; Li, T.-S. Total Ginsenosides Synergize with Ulinastatin against Septic Acute Lung Injury and Acute Respiratory Distress Syndrome. Int. J. Clin. Exp. Pathol. 2015, 8, 7385-7390.

88. Zhang, Y.; Sun, K.; Liu, Y.-Y.; Zhang, Y.-P.; Hu, B.-H.; Chang, X.; Yan, L.; Pan, C.-S.; Li, Q.; Fan, J.-Y.; et al. Ginsenoside $\mathrm{Rb} 1$ ameliorates lipopolysaccharide-induced albumin leakage from rat mesenteric venules by intervening in both trans- and paracellular pathway. Am. J. Physiol. Gastrointest. Liver Physiol. 2014, 306, G289-G300. [CrossRef]

89. Joh, E.-H.; Lee, I.-A.; Jung, I.-H.; Kim, D.-H. Ginsenoside Rb1 and its metabolite compound K inhibit IRAK-1 activation-The key step of inflammation. Biochem. Pharmacol. 2011, 82, 278-286. [CrossRef] [PubMed]

90. Yu, T.; Yang, Y.; Kwak, Y.-S.; Song, G.G.; Kim, M.-Y.; Rhee, M.H.; Cho, J.Y. Ginsenoside Rc from Panax ginseng exerts antiinflammatory activity by targeting TANK-binding kinase 1/interferon regulatory factor-3 and p38/ATF-2. J. Ginseng Res. 2017, 41, 127-133. [CrossRef] [PubMed]

91. Jiang, R.; Dong, J.; Li, X.; Du, F.; Jia, W.; Xu, F.; Wang, F.; Yang, J.; Niu, W.; Li, C. Molecular mechanisms governing different pharmacokinetics of ginsenosides and potential for ginsenoside-perpetrated herb-drug interactions on OATP1B3. Br. J. Pharmacol. 2015, 172, 1059-1073. [CrossRef]

92. Olaleye, O.; Niu, W.; Du, F.-F.; Wang, F.-Q.; Xu, F.; Pintusophon, S.; Lu, J.-L.; Yang, J.-L.; Li, C. Multiple circulating saponins from intravenous ShenMai inhibit OATP1Bs in vitro: Potential joint precipitants of drug interactions. Acta Pharmacol. Sin. 2019, 40, 833-849. [CrossRef] [PubMed]

93. Pintusophon, S.; Niu, W.; Duan, X.-N.; Olaleye, O.E.; Huang, Y.-H.; Wang, F.-Q.; Li, Y.-F.; Yang, J.-L.; Li, C. Intravenous formulation of Panax notoginseng root extract: Human pharmacokinetics of ginsenosides and potential for perpetrating drug interactions. Acta Pharmacol. Sin. 2019, 40, 1351-1363. [CrossRef]

94. You, Q.; Wang, J.; Jiang, L.; Chang, Y.; Li, W. Aqueous extract of Aconitum carmichaelii Debeaux attenuates sepsis-induced acute lung injury via regulation of TLR4/NF-KB pathway. Trop. J. Pharm. Res. 2020, 19, 533-539. [CrossRef]

95. Tanimura, Y.; Yoshida, M.; Ishiuchi, K.; Ohsawa, M.; Makino, T. Neoline is the active ingredient of processed aconite root against murine peripheral neuropathic pain model, and its pharmacokinetics in rats. J. Ethnopharmacol. 2019, 241, 111859. [CrossRef] [PubMed]

96. Li, Y.; Feng, Y.-F.; Liu, X.-T.; Li, Y.-C.; Zhu, H.-M.; Sun, M.-R.; Li, P.; Liu, B.; Yang, H. Songorine promotes cardiac mitochondrial biogenesis via Nrf2 induction during sepsis. Redox Biol. 2021, 38, 101771. [CrossRef]

97. Ma, J.; Kan, H.; Ma, Y.; Men, L.; Pi, Z.; Liu, Z.; Liu, Z. Qualitative and quantitative analysis of drug interactions: Fritillary mediating the transport of alkaloids in caco-2 cells by p-glycoprotein. Chem. Res. Chin. Univ. 2014, 30, 731-737. [CrossRef]

98. Park, J.-S.; Shin, J.A.; Jung, J.-S.; Hyun, J.-W.; Van Le, T.K.; Kim, D.-H.; Park, E.-M.; Kim, H.-S. Anti-Inflammatory Mechanism of Compound K in Activated Microglia and Its Neuroprotective Effect on Experimental Stroke in Mice. J. Pharmacol. Exp. Ther. 2011, 341, 59-67. [CrossRef]

99. Yang, C.-S.; Ko, S.-R.; Cho, B.-G.; Shin, N.-M.; Yuk, J.-M.; Li, S.; Kim, J.-M.; Evans, R.M.; Jung, J.-S.; Song, N.-K.; et al. The ginsenoside metabolite compound $\mathrm{K}$, a novel agonist of glucocorticoid receptor, induces tolerance to endotoxin-induced lethal shock. J. Cell. Mol. Med. 2008, 12, 1739-1753. [CrossRef]

100. Zhan, T.; Yao, N.; Wu, L.; Lu, Y.; Liu, M.; Liu, F.; Xiong, Y.; Xia, C. The major effective components in Shengmai Formula interact with sodium taurocholate co-transporting polypeptide. Phytomedicine 2019, 59, 152916. [CrossRef] [PubMed] 
101. Xia, C.; Sun, J.; Wang, G.; Shang, L.; Zhang, X.; Zhang, R.; Wang, X.; Hao, H.; Xie, L. Differential effect of Shenmai injection, a herbal preparation, on the cytochrome P450 3A-mediated 1'-hydroxylation and 4-hydroxylation of midazolam. Chem. Interact. 2009, 180, 440-448. [CrossRef]

102. Huang, X.; Wang, Y.; Zhang, Z.; Wang, Y.; Chen, X.; Wang, Y.; Gao, Y. Ophiopogonin D and EETs ameliorate Ang II-induced inflammatory responses via activating PPAR $\alpha$ in HUVECs. Biochem. Biophys. Res. Commun. 2017, 490, 123-133. [CrossRef]

103. Wang, Y.; Chen, Y.; Wang, H.; Cheng, Y.; Zhao, X. Specific Turn-On Fluorescent Probe with Aggregation-Induced Emission Characteristics for SIRT1 Modulator Screening and Living-Cell Imaging. Anal. Chem. 2015, 87, 5046-5049. [CrossRef] [PubMed]

104. Sun, Q.; Chen, L.; Gao, M.; Jiang, W.; Shao, F.; Li, J.; Wang, J.; Kou, J.; Yu, B. Ruscogenin inhibits lipopolysaccharide-induced acute lung injury in mice: Involvement of tissue factor, inducible NO synthase and nuclear factor (NF)- $\mathrm{KB}$. Int. Immunopharmacol. 2012, 12, 88-93. [CrossRef] [PubMed]

105. Ji, X.; Ding, B.; Wu, X.; Liu, F.; Yang, F. In vitro study on the effect of ophiopogonin D on the activity of cytochrome P450 enzymes. Xenobiotica 2021, 51, 262-267. [CrossRef] [PubMed]

106. Jiang, L.-P.; Zhao, J.; Cao, Y.-F.; Hong, M.; Sun, D.-X.; Sun, X.-Y.; Yin, J.; Zhu, Z.-T.; Fang, Z.-Z. The Inhibition of the Components from Shengmai Injection towards UDP-Glucuronosyltransferase. Evid.-Based Complement. Altern. Med. 2014, 2014, 1-9. [CrossRef] [PubMed]

107. Liu, S.; Lu, B. Schisantherin-A Alleviates Lipopolysaccharide-Induced Inflammation and Apoptosis in WI-38 Cells. Curr. Top. Nutraceutical Res. 2021, 19, 421-426. [CrossRef]

108. Bae, S.; Kim, J.; Choi, Y.; Lee, S.; Gong, J.; Choi, Y.-W.; Hwang, D. Novel Function of $\alpha$-Cubebenoate Derived from Schisandra chinensis as Lipogenesis Inhibitor, Lipolysis Stimulator and Inflammasome Suppressor. Molecules 2020, 25, 4995. [CrossRef]

109. Xu, J.-J.; Lu, C.-J.; Liu, Z.-J.; Zhang, P.; Guo, H.-L.; Wang, T.-T. Schizandrin B Protects LPS-Induced Sepsis via TLR4/NF-kB/MyD88 Signaling Pathway. Am. J. Transl. Res. 2018, 10, 1155-1163.

110. Kook, M.; Lee, S.K.; Kim, S.D.; Lee, H.Y.; Hwang, J.S.; Choi, Y.W.; Bae, Y.-S. Anti-septic activity of $\alpha$-cubebenoate isolated from Schisandra chinensis. BMB Rep. 2015, 48, 336-341. [CrossRef]

111. Wang, Y.; Du, P.; Jiang, D. Berberine functions as a negative regulator in lipopolysaccharide -induced sepsis by suppressing NF-кB and IL-6 mediated STAT3 activation. Pathog. Dis. 2020, 78, 47. [CrossRef] [PubMed]

112. He, Y.; Yuan, X.; Zuo, H.; Sun, Y.; Feng, A. Berberine Exerts a Protective Effect on Gut-Vascular Barrier via the Modulation of the Wnt/Beta-Catenin Signaling Pathway During Sepsis. Cell. Physiol. Biochem. 2018, 49, 1342-1351. [CrossRef]

113. Li, G.-X.; Wang, X.-M.; Jiang, T.; Gong, J.-F.; Niu, L.-Y.; Li, N. Berberine Prevents Intestinal Mucosal Barrier Damage During Early Phase of Sepsis in Rat through the Toll-Like Receptors Signaling Pathway. Korean J. Physiol. Pharmacol. 2015, 19, 1-7. [CrossRef]

114. Gao, M.-Y.; Chen, L.; Yang, L.; Yu, X.; Kou, J.-P.; Yu, B.-Y. Berberine inhibits LPS-induced TF procoagulant activity and expression through NF-kB/p65, Akt and MAPK pathway in THP-1 cells. Pharmacol. Rep. 2014, 66, 480-484. [CrossRef]

115. Zhang, Q.; Piao, X.-L.; Lu, T.; Wang, D.; Kim, S.W. Preventive effect of Coptis chinensis and berberine on intestinal injury in rats challenged with lipopolysaccharides. Food Chem. Toxicol. 2011, 49, 61-69. [CrossRef]

116. Kumar, A.; Ekavali, K.C.; Mukherjee, M.; Pottabathini, R.; Dhull, D.K. Current knowledge and pharmacological profile of berberine: An update. Eur. J. Pharmacol. 2015, 761, 288-297. [CrossRef]

117. Lee, S.Y.; Jang, H.; Lee, J.-Y.; Ma, J.Y.; Oh, S.J.; Kim, S.K. Inhibitory effects of Hwang-Ryun-Hae-Dok-Tang on cytochrome P450 in human liver microsomes. Xenobiotica 2014, 45, 131-138. [CrossRef]

118. Song, P.; Shen, D.-F.; Meng, Y.-Y.; Kong, C.-Y.; Zhang, X.; Yuan, Y.-P.; Yan, L.; Tang, Q.-Z.; Ma, Z.-G. Geniposide protects against sepsis-induced myocardial dysfunction through AMPK $\alpha$-dependent pathway. Free. Radic. Biol. Med. 2020, 152, 186-196. [CrossRef]

119. Liu, J.; Zhao, N.; Shi, G.; Wang, H. Geniposide ameliorated sepsis-induced acute kidney injury by activating PPAR $\gamma$. Aging 2020, 12, 22744-22758. [CrossRef] [PubMed]

120. Cho, H.; Kim, S.; Choi, J.; Lee, S. Genipin alleviates sepsis-induced liver injury by restoring autophagy. Br. J. Pharmacol. 2016, 173, 980-991. [CrossRef]

121. Liu, H.; Chen, Y.-F.; Li, F.; Zhang, H.-Y. Fructus Gardenia (Gardenia jasminoides J. Ellis) phytochemistry, pharmacology of cardiovascular, and safety with the perspective of new drugs development. J. Asian Nat. Prod. Res. 2012, 15, 94-110. [CrossRef]

122. Yang, X.; Cai, Q.; He, J.; Chu, X.; Wei, M.; Feng, X.; Xie, X.; Huo, M.; Liu, J.; Wei, J.; et al. Geniposide, an Iridoid Glucoside Derived from Gardenia jasminoides, Protects against Lipopolysaccharide-induced Acute Lung Injury in Mice. Planta Med. 2012, 78, 557-564. [CrossRef]

123. Zheng, X.; Yang, D.; Liu, X.; Wang, N.; Li, B.; Cao, H.; Lu, Y.; Wei, G.; Zhou, H.; Zheng, J. Identification of a new anti-LPS agent, geniposide, from Gardenia jasminoides Ellis, and its ability of direct binding and neutralization of lipopolysaccharide in vitro and in vivo. Int. Immunopharmacol. 2010, 10, 1209-1219. [CrossRef]

124. Duan, X.-Y.; Sun, Y.; Zhao, Z.-F.; Shi, Y.-Q.; Ma, X.-Y.; Tao, L.; Liu, M.-W. Baicalin attenuates LPS-induced alveolar type II epithelial cell A549 injury by attenuation of the FSTL1 signaling pathway via increasing miR-200b-3p expression. Innate Immun. 2021, 27, 294-312. [CrossRef]

125. Kuo, S.-W.; Su, W.-L.; Chou, T.-C. Baicalin improves the survival in endotoxic mice and inhibits the inflammatory responses in LPS-treated RAW 264.7 macrophages. Eur. J. Inflamm. 2020, 18, 18. [CrossRef]

126. Zhu, Y.; Fu, Y.; Lin, H. Baicalin Inhibits Renal Cell Apoptosis and Protects Against Acute Kidney Injury in Pediatric Sepsis. Med. Sci. Monit. 2016, 22, 5109-5115. [CrossRef] 
127. Chen, H.-M.; Lou, S.-F.; Hsu, J.-H.; Chen, T.-J.; Cheng, T.-L.; Chiu, C.-C.; Yeh, J.-L. Baicalein Inhibits HMGB1 Release and MMP-2/-9 Expression in Lipopolysaccharide-induced Cardiac Hypertrophy. Am. J. Chin. Med. 2014, 42, 785-797. [CrossRef]

128. Noh, K.; Kang, Y.; Nepal, M.R.; Jeong, K.S.; Oh, D.G.; Kang, M.J.; Lee, S.; Kang, W.; Jeong, H.G.; Jeong, T.C. Role of Intestinal Microbiota in Baicalin-Induced Drug Interaction and Its Pharmacokinetics. Molecules 2016, 21, 337. [CrossRef]

129. Dai, J.; Guo, W.; Tan, Y.; Niu, K.; Zhang, J.; Liu, C.; Yang, X.; Tao, K.; Chen, Z.; Dai, J. Wogonin alleviates liver injury in sepsis through Nrf2-mediated NF-kB signalling suppression. J. Cell. Mol. Med. 2021, 25, 5782-5798. [CrossRef]

130. Gao, Y.-Z.; Zhao, L.-F.; Ma, J.; Xue, W.-H.; Zhao, H. Protective mechanisms of wogonoside against Lipopolysaccharide/Dgalactosamine-induced acute liver injury in mice. Eur. J. Pharmacol. 2016, 780, 8-15. [CrossRef]

131. Lee, J.Y.; Park, W. Anti-Inflammatory Effect of Wogonin on RAW 264.7 Mouse Macrophages Induced with PolyinosinicPolycytidylic Acid. Molecules 2015, 20, 6888-6900. [CrossRef]

132. Zhang, L.; Ren, Y.; Yang, C.; Guo, Y.; Zhang, X.; Hou, G.; Guo, X.; Sun, N.; Liu, Y. Wogonoside Ameliorates LipopolysaccharideInduced Acute Lung Injury in Mice. Inflammation 2014, 37, 2006-2012. [CrossRef] [PubMed]

133. Shao, Y.-X.; Zhao, P.; Li, Z.; Liu, M.; Liu, P.; Huang, M.; Luo, H.-B. The molecular basis for the inhibition of human cytochrome P450 1A2 by oroxylin and wogonin. Eur. Biophys. J. 2012, 41, 297-306. [CrossRef] [PubMed]

134. Zhang, Z.; Wang, Y.; Shan, Y.; Zhou, R.; Yin, W. Oroxylin A alleviates immunoparalysis of CLP mice by degrading CHOP through interacting with FBXO15. Sci. Rep. 2020, 10, 1-15. [CrossRef]

135. Tseng, T.-L.; Chen, M.-F.; Hsu, Y.-H.; Lee, T.J. OroxylinA reverses lipopolysaccharide-induced adhesion molecule expression and endothelial barrier disruption in the rat aorta. Toxicol. Appl. Pharmacol. 2020, 400, 115070. [CrossRef] [PubMed]

136. Li, H.-F.; Wu, Y.-L.; Tseng, T.-L.; Chao, S.-W.; Lin, H.; Chen, H.-H. Inhibition of miR-155 potentially protects against lipopolysaccharide-induced acute lung injury through the IRF2BP2-NFAT1 pathway. Am. J. Physiol. Physiol. 2020, 319, C1070-C1081. [CrossRef]

137. Lee, J.Y.; Park, W. Anti-inflammatory effects of oroxylin A on RAW 264.7 mouse macrophages induced with polyinosinicpolycytidylic acid. Exp. Ther. Med. 2016, 12, 151-156. [CrossRef]

138. Ku, S.-K.; Han, M.-S.; Lee, M.Y.; Lee, Y.-M.; Bae, J.-S. Inhibitory effects of oroxylin A on endothelial protein C receptor shedding in vitro and in vivo. BMB Rep. 2014, 47,336-341. [CrossRef]

139. Tseng, T.-L.; Chen, M.-F.; Tsai, M.-J.; Hsu, Y.-H.; Chen, C.-P.; Lee, T.J.F. Oroxylin-A Rescues LPS-Induced Acute Lung Injury via Regulation of NF-kB Signaling Pathway in Rodents. PLoS ONE 2012, 7, e47403. [CrossRef] [PubMed]

140. Ren, G.; Qin, Z.; Yang, N.; Chen, H.; Fu, K.; Lu, C.; Lu, Y.; Li, N.; Zhang, Y.; Chen, X.; et al. Interactions between Oroxylin A with the solute carrier transporters and ATP-binding cassette transporters: Drug transporters profile for this flavonoid. Chem. Interact. 2020, 324, 109097. [CrossRef]

141. Li, Y.; Yu, H.; Jin, Y.; Li, M.; Qu, C. Verbascoside Alleviates Atopic Dermatitis-Like Symptoms in Mice via Its Potent AntiInflammatory Effect. Int. Arch. Allergy Immunol. 2018, 175, 220-230. [CrossRef]

142. Campo, G.; Marchesini, J.; Bristot, L.; Monti, M.; Gambetti, S.; Pavasini, R.; Pollina, A.; Ferrari, R. The in vitro effects of verbascoside on human platelet aggregation. J. Thromb. Thrombolysis 2012, 34, 318-325. [CrossRef]

143. Speranza, L.; Franceschelli, S.; Pesce, M.; Reale, M.; Menghini, L.; Vinciguerra, I.; De Lutiis, M.A.; Felaco, M.; Grilli, A. Antiinflammatory effects in THP-1 cells treated with verbascoside. Phytother. Res. 2010, 24, 1398-1404. [CrossRef]

144. Li, A.; Dong, L.; Duan, M.-L.; Sun, K.; Liu, Y.-Y.; Wang, M.-X.; Deng, J.-N.; Fan, J.-Y.; Wang, B.-E.; Han, J.-Y. Emodin Improves Lipopolysaccharide-Induced Microcirculatory Disturbance in Rat Mesentery. Microcirculation 2013, 20, 617-628. [CrossRef]

145. Dai, S.; Ye, B.; Chen, L.; Hong, G.; Zhao, G.; Lu, Z. Emodin alleviates LPS -induced myocardial injury through inhibition of NLRP3 inflammasome activation. Phytother. Res. 2021, 35, 5203-5213. [CrossRef]

146. Ding, Y.; Liu, P.; Chen, Z.-L.; Zhang, S.-J.; Wang, Y.-Q.; Cai, X.; Luo, L.; Zhou, X.; Zhao, L. Emodin Attenuates LipopolysaccharideInduced Acute Liver Injury via Inhibiting the TLR4 Signaling Pathway in vitro and in vivo. Front. Pharmacol. $2018,9,962$. [CrossRef]

147. Zhu, T.; Zhang, W.; Feng, S.-J.; Yu, H.-P. Emodin suppresses LPS-induced inflammation in RAW264.7 cells through a PPAR $\gamma$ dependent pathway. Int. Immunopharmacol. 2016, 34, 16-24. [CrossRef] [PubMed]

148. Yin, J.-T.; Wan, B.; Liu, D.-D.; Wan, S.-X.; Fu, H.-Y.; Wan, Y.; Zhang, H.; Chen, Y. Emodin alleviates lung injury in rats with sepsis. J. Surg. Res. 2016, 202, 308-314. [CrossRef] [PubMed]

149. Chen, Y.-K.; Xu, Y.-K.; Zhang, H.; Yin, J.-T.; Fan, X.; Liu, D.-D.; Fu, H.-Y.; Wan, B. Emodin alleviates jejunum injury in rats with sepsis by inhibiting inflammation response. Biomed. Pharmacother. 2016, 84, 1001-1007. [CrossRef]

150. Sun, Y.-N.; Sun, L.-J.; Liu, S.-Q.; Song, J.; Cheng, J.-J.; Liu, J. Effect of Emodin on Aquaporin 5 Expression in Rats with SepsisInduced Acute Lung Injury. J. Tradit. Chin. Med. 2015, 35, 679-684. [CrossRef]

151. Wang, D.; Wang, X.-H.; Yu, X.; Cao, F.; Cai, X.; Chen, P.; Li, M.; Feng, Y.; Li, H.; Wang, X. Pharmacokinetics of Anthraquinones from Medicinal Plants. Front. Pharmacol. 2021, 12, 638993. [CrossRef]

152. Li, T.-Q.; Ma, J.-X.; Zhou, Y.-D. Investigation of Clinical Practice and Side Effects of Shenfu Injection. China J. Chin. Mater. Med. 2009, 9, 319-322.

153. Wang, Z.-F.; Yu, J.-Y.; Xie, Y.-M. Clinical safety imtensive hospital monitoring on Shenfu injection with 30106 cases. China J. Chin. Mater. Med. 2017, 42, 2871-2876. [CrossRef]

154. Fink, M.P. Gastrointestinal mucosal injury in experimental models of shock, trauma, and sepsis. Crit. Care Med. 1991, 19, 627-641. [CrossRef] 
155. Aderinto-Adike, A.; Quigley, E.M.M. Gastrointestinal motility problems in critical care: A clinical perspective. J. Dig. Dis. 2014, 15, 335-344. [CrossRef]

156. Xing, X.; Jiang, R.; Wang, L.; Lei, S.; Zhi, Y.; Wu, Y.; Zhu, M.; Huang, L.; Xia, G.; Chen, Z. Shenfu injection alleviates intestine epithelial damage in septic rats. Am. J. Emerg. Med. 2015, 33, 1665-1670. [CrossRef] [PubMed]

157. Marik, P.E.; Varon, J. Sepsis: State of the art. Dis. Mon. 2001, 47, 462-532. [CrossRef]

158. Jin, S.; Jiang, R.; Lei, S.; Jin, L.; Zhu, C.; Feng, W.; Shen, Y. Shenfu injection prolongs survival and protects the intestinal mucosa in rats with sepsis by modulating immune response. Turk. J. Gastroenterol. 2019, 30, 364-371. [CrossRef]

159. Liu, X.; Liu, R.; Dai, Z.; Wu, H.; Lin, M.; Tian, F.; Gao, Z.; Zhao, X.; Sun, Y.; Pu, X. Effect of Shenfu injection on lipopolysaccharide (LPS)-induced septic shock in rabbits. J. Ethnopharmacol. 2019, 234, 36-43. [CrossRef] [PubMed]

160. Chen, R.-J.; Rui, Q.-L.; Wang, Q.; Tian, F.; Wu, J.; Kong, X.-Q. Shenfu injection attenuates lipopolysaccharide-induced myocardial inflammation and apoptosis in rats. Chin. J. Nat. Med. 2020, 18, 226-233. [CrossRef]

161. Xu, P.; Zhang, W.-Q.; Xie, J.; Wen, Y.-S.; Zhang, G.-X.; Lu, S.-Q. Shenfu injection prevents sepsis-induced myocardial injury by inhibiting mitochondrial apoptosis. J. Ethnopharmacol. 2020, 261, 113068. [CrossRef]

162. Wu, W.; Jiang, R.-L.; Wang, L.-C.; Lei, S.; Xing, X.; Zhi, Y.-H.; Wu, J.-N.; Wu, Y.-C.; Zhu, M.-F.; Huang, L.-Q. Effect of Shenfu injection on intestinal mucosal barrier in a rat model of sepsis. Am. J. Emerg. Med. 2015, 33, 1237-1243. [CrossRef]

163. Liu, X.; Ai, F.; Li, H.; Xu, Q.; Mei, L.; Miao, J.; Wen, Q.; Zhang, C.; Zhang, S.; Zhou, J.; et al. Anti-Inflammatory Effects of Shenfu Injection against Acute Lung Injury through Inhibiting HMGB1-NF-кB Pathway in a Rat Model of Endotoxin Shock. Evid.-Based Complement. Altern. Med. 2019, 2019, 1-10. [CrossRef] [PubMed]

164. Liu, Y.; Zhang, N.; Shi, S.-P.; Song, Q.-Q.; Li, J.; Song, Y.-L.; Tu, P.-F. Simultaneous determination of 14 organic acids in Shenfu injection by hydrophilic interaction chromatography-tandem mass spectrometry. China J. Chin. Mater. Med. 2016, 41, 3342-3348. [CrossRef]

165. Ge, A.-H.; Li, J.; Donnapee, S.; Bai, Y.; Liu, J.; He, J.; Liu, E.-W.; Kang, L.-Y.; Gao, X.-M.; Chang, Y.-X. Simultaneous determination of 2 aconitum alkaloids and 12 ginsenosides in Shenfu injection by ultraperformance liquid chromatography coupled with a photodiode array detector with few markers to determine multicomponents. J. Food Drug Anal. 2015, 23, 267-278. [CrossRef]

166. Yang, H.; Liu, L.; Gao, W.; Liu, K.; Qi, L.-W.; Li, P. Direct and comprehensive analysis of ginsenosides and diterpene alkaloids in Shenfu injection by combinatory liquid chromatography-mass spectrometric techniques. J. Pharm. Biomed. Anal. 2014, 92, 13-21. [CrossRef] [PubMed]

167. Song, Y.; Zhang, N.; Shi, S.; Li, J.; Zhang, Q.; Zhao, Y.; Jiang, Y.; Tu, P. Large-scale qualitative and quantitative characterization of components in Shenfu injection by integrating hydrophilic interaction chromatography, reversed phase liquid chromatography, and tandem mass spectrometry. J. Chromatogr. A 2015, 1407, 106-118. [CrossRef]

168. Li, P.; Lv, B.; Jiang, X.; Wang, T.; Ma, X.; Chang, N.; Wang, X.; Gao, X. Identification of NF-kB inhibitors following Shenfu injection and bioactivity-integrated UPLC/Q-TOF-MS and screening for related anti-inflammatory targets in vitro and in silico. J. Ethnopharmacol. 2016, 194, 658-667. [CrossRef] [PubMed]

169. Li, Z.; Zhang, R.; Wang, X.; Hu, X.; Chen, Y.; Liu, Q. Simultaneous determination of seven ginsenosides in rat plasma by high-performance liquid chromatography coupled to time-of-flight mass spectrometry: Application to pharmacokinetics of Shenfu injection. Biomed. Chromatogr. 2015, 29, 167-175. [CrossRef]

170. Liu, H.; Yang, J.; Du, F.; Gao, X.; Ma, X.; Huang, Y.; Xu, F.; Niu, W.; Wang, F.; Mao, Y.; et al. Absorption and Disposition of Ginsenosides after Oral Administration of Panax notoginseng Extract to Rats. Drug Metab. Dispos. 2009, 37, 2290-2298. [CrossRef] [PubMed]

171. He, J.-L.; Zhou, S.-S.; Ma, Z.-C.; Liang, Q.-D.; Wang, Y.-G.; Tan, H.-L.; Xiao, C.-R.; Tang, X.-L.; Gao, Y. Material Basis of Shenfu Injection Based on UPLC-Q-TOF/MS. Chin. Pharmacol. Bull. 2014, 30, 429-433. [CrossRef]

172. Zhang, Y.; Tian, D.; Huang, Y.; Li, L.; Mao, J.; Tian, J.; Ding, J. Pharmacokinetic evaluation of Shenfu Injection in beagle dogs after intravenous drip administration. Acta Pharm. Sin. B 2016, 6, 584-592. [CrossRef]

173. Fu, S.; Zhang, J.; Gao, X.; Xia, Y.; Ferrelli, R.M.; Fauci, A.; Guerra, R.; Hu, L. Clinical practice of traditional Chinese medicines for chronic heart failure. Hear. Asia 2010, 2, 24-27. [CrossRef]

174. Huang, X.; Duan, X.; Wang, K.; Wu, J.; Zhang, X. Shengmai injection as an adjunctive therapy for the treatment of chronic obstructive pulmonary disease: A systematic review and meta-analysis. Complement. Ther. Med. 2019, 43, 140-147. [CrossRef]

175. Ma, D.-H.; Xi, R.; Sun, J. Adverse Reaction Characteristics and Influencing Factors of Shengmai Injections. Pharm. Clin. Res. 2016, 24, 324-327. [CrossRef]

176. Ha, Y.-X.; Wang, X.-P.; Huang, P.; Zhuang, R.; Xu, X.-L.; Li, B.; Liu, Q.-Q. Effect of Shengmai Injection on Septic Shock, a Systematic Review and Meta-Analysis. J. Emerg. Tradit. Chin. Med. 2019, 28, 1893-1898. [CrossRef]

177. Lu, J.; Yu, Y.; Wang, X.-J.; Chai, R.-P.; Lyu, X.-K.; Deng, M.-H.; Hu, M.-G.; Qi, Y.; Chen, X. Mechanism of Shengmai Injection on Anti-Sepsis and Protective Activities of Intestinal Mucosal Barrier in Mice. Chin. J. Integr. Med. 2021, 2021, 1-6. [CrossRef]

178. Cao, Y.; Han, X.; Pan, H.; Jiang, Y.; Peng, X.; Xiao, W.; Rong, J.; Chen, F.; He, J.; Zou, L.; et al. Emerging protective roles of shengmai injection in septic cardiomyopathy in mice by inducing myocardial mitochondrial autophagy via caspase-3/Beclin-1 axis. Inflamm. Res. 2020, 69, 41-50. [CrossRef]

179. Chai, R.-P.; Zhang, Y.-H.; Lu, J.; Wang, T.-J.; Chen, X. Research on Mechanism of Shengmai Injection in the Treatment of Sepsis Based on Metabolomics. China J. Pharm. Econ. 2019, 14, 30-34. [CrossRef] 
180. Zheng, B.-H.; Zhan, S.-Y.; Zhou, H.-Y.; Feng, Y.-H.; Fang, M.-T.; Zheng, Y.-X.; Liu, G.-Q.; Li, M.-J. Research Progress on Material Composition, Pre-clinical Pharmacokinetic and Pharmacodynamic Studies of Shengmai Injection. Chin. Tradit. Herb. Drugs 2020, 51, 5360-5371. [CrossRef]

181. Zheng, C.; Hao, H.; Wang, X.; Wu, X.; Wang, G.; Sang, G.; Liang, Y.; Xie, L.; Xia, C.; Yao, X. Diagnostic fragment-ion-based extension strategy for rapid screening and identification of serial components of homologous families contained in traditional Chinese medicine prescription using high-resolution LC-ESI- IT-TOF/MS: Shengmai injection as an example. J. Mass Spectrom. 2008, 44, 230-244. [CrossRef]

182. Zhao, C.; Liu, H.; Miao, P.; Wang, H.; Yu, H.; Wang, C.; Li, Z. A Strategy for Selecting "Q-Markers" of Chinese Medical Preparation via Components Transfer Process Analysis with Application to the Quality Control of Shengmai Injection. Molecules 2019, 24, 1811. [CrossRef]

183. Wu, F.; Sun, H.; Wei, W.; Han, Y.; Wang, P.; Dong, T.; Yan, G.; Wang, X. Rapid and global detection and characterization of the constituents in ShengMai San by ultra-performance liquid chromatography-high-definition mass spectrometry. J. Sep. Sci. 2011, 34, 3194-3199. [CrossRef]

184. Cheng, Y.-Y.; Tsai, T.-H. Analysis of Sheng-Mai-San, a Ginseng-Containing Multiple Components Traditional Chinese Herbal Medicine Using Liquid Chromatography Tandem Mass Spectrometry and Physical Examination by Electron and Light Microscopies. Molecules 2016, 21, 1159. [CrossRef] [PubMed]

185. Zheng, Y.; Fan, C.; Liu, M.; Chen, Y.; Lu, Z.; Xu, N.; Huang, H.; Zeng, H.; Liu, S.; Cao, H.; et al. Overall quality control of the chemical and bioactive consistency of ShengMai Formula. J. Pharm. Biomed. Anal. 2020, 189, 113411. [CrossRef] [PubMed]

186. Li, X.; Chen, H.; Jia, W.; Xie, G. A Metabolomics-Based Strategy for the Quality Control of Traditional Chinese Medicine: Shengmai Injection as a Case Study. Evid.-Based Complement. Altern. Med. 2013, 2013, 1-8. [CrossRef] [PubMed]

187. Li, F.; Cheng, T.-F.; Dong, X.; Li, P.; Yang, H. Global analysis of chemical constituents in Shengmai injection using high performance liquid chromatography coupled with tandem mass spectrometry. J. Pharm. Biomed. Anal. 2016, 117, 61-72. [CrossRef] [PubMed]

188. Lu, J.; Lyu, X.; Chai, R.; Yu, Y.; Deng, M.; Zhan, X.; Dong, Z.; Chen, X. Investigation of the Mechanism of Shengmai Injection on Sepsis by Network Pharmacology Approaches. Evid.-Based Complement. Altern. Med. 2020, 2020, 1-11. [CrossRef]

189. Zhang, Y.; Hu, Y.; Li, M.; Wang, J.; Guo, G.; Li, F.; Yu, B.; Kou, J. The Traditional Chinese Medicine Compound, GRS, Alleviates Blood-Brain Barrier Dysfunction. Drug Des. Dev. Ther. 2020, 14, 933-947. [CrossRef] [PubMed]

190. Zhan, S.; Shao, Q.; Fan, X.; Li, Z. Development of a sensitive LC-MS/MS method for simultaneous quantification of eleven constituents in rat serum and its application to a pharmacokinetic study of a Chinese medicine Shengmai injection. Biomed. Chromatogr. 2015, 29, 275-284. [CrossRef]

191. Zhan, S.-Y.; Shao, Q.; Fan, X.-H.; Li, Z.; Cheng, Y.-Y. Tissue distribution and excretion of herbal components after intravenous administration of a Chinese medicine (Shengmai injection) in rat. Arch. Pharmacal Res. 2014, 1-12. [CrossRef]

192. Han, Y.; Sun, H.; Zhang, A.; Wu, F.; Wei, W.; Dong, T.; Wang, X. Characterization and Pharmacokinetic Study of Multiple Constituents from Shengmai San. In Serum Pharmacochemistry of Traditional Chinese Medicine; Wang, X., Ed.; Academic Press: Cambridge, MA, USA, 2017; pp. 103-117.

193. Han, Y.; Wu, F.; Zhang, A.; Sun, H.; Wei, W.; Wang, X. Characterization of multiple constituents in rat plasma after oral administration of Shengmai San using ultra-performance liquid chromatography coupled with electrospray ionization/quadrupole-timeof-flight high-definition mass spectrometry. Anal. Methods 2015, 7, 830-837. [CrossRef]

194. Qiang, T.-T.; Li, Y.-P.; Wang, X.-L. Inhibitory Effect of Shengmai Injection on CYP450 Enzyme and Transporter in Vitro. Chin. Tradit. Herb. Drugs 2021, 52, 3568-3575. [CrossRef]

195. Chiang, T.-Y.; Wang, H.-J.; Wang, Y.-C.; Tan, E.C.-H.; Lee, I.-J.; Yun, C.-H.; Ueng, Y.-F. Effects of Shengmai San on key enzymes involved in hepatic and intestinal drug metabolism in rats. J. Ethnopharmacol. 2021, 271, 113914. [CrossRef]

196. Liang, Y.; Zhou, Y.; Zhang, J.; Rao, T.; Zhou, L.; Xing, R.; Wang, Q.; Fu, H.; Hao, K.; Xie, L.; et al. Pharmacokinetic Compatibility of Ginsenosides and Schisandra Lignans in Shengmai-san: From the Perspective of P-Glycoprotein. PLoS ONE 2014, 9 , e98717. [CrossRef] [PubMed]

197. Wen, J.; Wang, R.; Liu, H.; Tong, Y.; Wei, S.; Zhou, X.; Li, H.; Jing, M.; Wang, M.; Zhao, Y. Potential therapeutic effect of Qingwen Baidu Decoction against Corona Virus Disease 2019: A mini review. Chin. Med. 2020, 15, 1-17. [CrossRef] [PubMed]

198. Wang, P.; Huang, H.; Zhong, J.; Cai, H.; Huang, Y.; Chen, D.; Huang, Y.; Li, S.; Cao, Q.; Peng, X. Qinwen Baidu decoction for sepsis A Protocol for a Systematic Review and Meta-Analysis. Medicine 2019, 98, e14761. [CrossRef]

199. Sun, Y.-Y.; Li, Z.-J.; Wang, J.-D. Clinical observation on treatment of 18 patients with pulmonary infection after renal transplantation by integrative traditional Chinese and Western medicine. Chin. J. Integr. Tradit. West. Med. 2005, 25, 797-800. [CrossRef]

200. Yu, Z.-M.; Liu, Z.-H.; Chen, J.; Zeng, Q. Anti-inflammatory effect of Qingwen Baidu Decoction in sepsis rats. Chin. J. Integr. Med. 2014, 20, 934-943. [CrossRef]

201. Zhang, F.-R.; Zhu, N.; Li, Z.-Y.; Tang, S.-H. Intervention mechanism of Qingwen Baidu Yin on cytokine storm based on network pharmacology. China J. Chin. Mater. Med. 2020, 45, 1499-1508. [CrossRef]

202. Chen, J.-P.; Zhang, K.-X.; Liu, Y.; Gai, X.-H.; Ren, T.; Liu, S.-X.; Tian, C.-W. Research Progress on Chemical Constituents and Pharmacological Actions of Rehmannia Glutinosa. Chin. Tradit. Herb. Drugs 2021, 52, 1772-1784. [CrossRef]

203. Liu, R.; Duan, J.-A.; Wang, M.; Shang, E.; Guo, J.; Tang, Y. Analysis of active components of rhinoceros, water buffalo and yak horns using two-dimensional electrophoresis and ethnopharmacological evaluation. J. Sep. Sci. 2011, 34, 354-362. [CrossRef] 
204. Qi, Y.; Zhang, Q.; Zhu, H. Huang-Lian Jie-Du decoction: A review on phytochemical, pharmacological and pharmacokinetic investigations. Chin. Med. 2019, 14, 1-22. [CrossRef] [PubMed]

205. Chen, L.; Li, M.; Yang, Z.; Tao, W.; Wang, P.; Tian, X.; Li, X.; Wang, W. Gardenia jasminoides Ellis: Ethnopharmacology, phytochemistry, and pharmacological and industrial applications of an important traditional Chinese medicine. J. Ethnopharmacol. 2020, 257, 112829. [CrossRef]

206. Zhang, L.; Wang, Y.; Yang, D.; Zhang, C.; Zhang, N.; Li, M.; Liu, Y. Platycodon grandiflorus-An Ethnopharmacological, phytochemical and pharmacological review. J. Ethnopharmacol. 2015, 164, 147-161. [CrossRef]

207. Wang, Z.-L.; Wang, S.; Kuang, Y.; Hu, Z.-M.; Qiao, X.; Ye, M. A comprehensive review on phytochemistry, pharmacology, and flavonoid biosynthesis of Scutellaria baicalensis. Pharm. Biol. 2018, 56, 465-484. [CrossRef]

208. Wang, Y.; Dan, Y.; Yang, D.; Hu, Y.; Zhang, L.; Zhang, C.; Zhu, H.; Cui, Z.; Li, M.; Liu, Y. The genus Anemarrhena Bunge: A review on ethnopharmacology, phytochemistry and pharmacology. J. Ethnopharmacol. 2014, 153, 42-60. [CrossRef] [PubMed]

209. Tan, Y.-Q.; Chen, H.-W.; Li, J.; Wu, Q.-J. Efficacy, Chemical Constituents, and Pharmacological Actions of Radix Paeoniae Rubra and Radix Paeoniae Alba. Front. Pharmacol. 2020, 11, 1054. [CrossRef] [PubMed]

210. Ren, D.; Shen, Z.-Y.; Qin, L.-P.; Zhu, B. Pharmacology, phytochemistry, and traditional uses of Scrophularia ningpoensis Hemsl. J. Ethnopharmacol. 2021, 269, 113688. [CrossRef] [PubMed]

211. Wang, Z.; Xia, Q.; Liu, X.; Liu, W.; Huang, W.; Mei, X.; Luo, J.; Shan, M.; Lin, R.; Zou, D.; et al. Phytochemistry, pharmacology, quality control and future research of Forsythia suspensa (Thunb.) Vahl: A review. J. Ethnopharmacol. 2018, 210, 318-339. [CrossRef]

212. Chen, Y. Review on Research of the Chemical Constituents and Pharmacological Activities of Lophatherum Gracile Brongn. Asia-Pac. Tradit. Med. 2014, 10, 50-52.

213. Qiao, X.; Song, W.; Ji, S.; Wang, Q.; Guo, D.-A.; Ye, M. Separation and characterization of phenolic compounds and triterpenoid saponins in licorice (Glycyrrhiza uralensis) using mobile phase-dependent reversed-phase $\times$ reversed-phase comprehensive two-dimensional liquid chromatography coupled with mass spectrometry. J. Chromatogr. A 2015, 1402, 36-45. [CrossRef]

214. Wang, Z.; He, C.; Peng, Y.; Chen, F.; Xiao, P. Origins, Phytochemistry, Pharmacology, Analytical Methods and Safety of Cortex Moutan (Paeonia suffruticosa Andrew): A Systematic Review. Molecules 2017, 22, 946. [CrossRef]

215. Zheng, Y.; Liu, S.; Fan, C.; Zeng, H.; Huang, H.; Tian, C.; Lu, Z.; Cao, H.; Liu, J.; Yu, L. Holistic quality evaluation of Qingwen Baidu Decoction and its anti-inflammatory effects. J. Ethnopharmacol. 2020, 263, 113145. [CrossRef] [PubMed]

216. Zhang, Q.; Lei, H.-M.; Wang, P.-L.; Ma, Z.-Q.; Zhang, Y.; Wu, J.-J.; Nie, J.; Chen, S.-J.; Han, W.-J.; Wang, Q.; et al. Bioactive Components from Qingwen Baidu Decoction against LPS-Induced Acute Lung Injury in Rats. Molecules 2017, 22, 692. [CrossRef]

217. Mao, Z.; Wang, H. Effects of Xuanbai Chengqi decoction on lung compliance for patients with exogenous pulmonary acute respiratory distress syndrome. Drug Des. Dev. Ther. 2016, 10, 793-798. [CrossRef]

218. Fan, T.; Chen, Y.; Bai, Y.; Ma, F.; Wang, H.; Yang, Y.; Chen, J.; Lin, Y. Analysis of medication characteristics of traditional Chinese medicine in treating COVID-19 based on data mining. J. Zhejiang Univ. Med. Sci 2020, 49, 260-269. [CrossRef]

219. Su, K.-L.; Xiong, X.-J. Treatment strategy and thought on classical herbal formulae for coronavirus disease 2019. China J. Chin. Mater. Med. 2021, 46, 494-503. [CrossRef]

220. Yin, X.; Cheng, N.; Zhu, J. Xuanbai Chengqi decoction plus Western Medicine in treatment of severe pneumonia with symptom pattern of phlegm-heat obstructing lung: A Meta-analysis. J. Tradit. Chin. Med. 2021, 41, 17-25. [CrossRef] [PubMed]

221. Lelubre, C.; Vincent, J.-L. Mechanisms and treatment of organ failure in sepsis. Nat. Rev. Nephrol. 2018, 14, 417-427. [CrossRef]

222. Haak, B.W.; Wiersinga, W.J. The role of the gut microbiota in sepsis. Lancet Gastroenterol. Hepatol. 2017, 2, 135-143. [CrossRef]

223. Zaborin, A.; Smith, D.; Garfield, K.; Quensen, J.; Shakhsheer, B.; Kade, M.; Tirrell, M.; Tiedje, J.; Gilbert, J.A.; Zaborina, O.; et al. Membership and Behavior of Ultra-Low-Diversity Pathogen Communities Present in the Gut of Humans during Prolonged Critical Illness. mBio 2014, 5, e01361-14. [CrossRef]

224. Rajilić-Stojanović, M.; De Vos, W.M. The first 1000 cultured species of the human gastrointestinal microbiota. FEMS Microbiol. Rev. 2014, 38, 996-1047. [CrossRef]

225. Deitch, E.A. Bacterial translocation or lymphatic drainage of toxic products from the gut: What is important in human beings? Surgery 2002, 131, 241-244. [CrossRef]

226. Dickson, R.P.; Singer, B.; Newstead, M.W.; Falkowski, N.R.; Erb-Downward, J.R.; Standiford, T.J.; Huffnagle, G.B. Enrichment of the lung microbiome with gut bacteria in sepsis and the acute respiratory distress syndrome. Nat. Microbiol. 2016, 1, 1-9. [CrossRef]

227. Mu, S.; Zhang, J.; Du, S.; Zhu, M.; Wei, W.; Xiang, J.; Wang, J.; Han, Y.; Zhao, Y.; Zheng, H.; et al. Gut microbiota modulation and anti-inflammatory properties of Xuanbai Chengqi decoction in septic rats. J. Ethnopharmacol. 2021, 267, 113534. [CrossRef] [PubMed]

228. Zhu, H.; Wang, S.; Shan, C.; Li, X.; Tan, B.; Chen, Q.; Yang, Y.; Yu, H.; Yang, A. Mechanism of protective effect of xuan-bai-cheng-qi decoction on LPS-induced acute lung injury based on an integrated network pharmacology and RNA-sequencing approach. Respir. Res. 2021, 22, 1-14. [CrossRef]

229. Cao, Y.-J.; Pu, Z.-J.; Tang, Y.-P.; Shen, J.; Chen, Y.-Y.; Kang, A.; Zhou, G.-S.; Duan, J.-A. Advances in bio-active constituents, pharmacology and clinical applications of rhubarb. Chin. Med. 2017, 12, 1-12. [CrossRef]

230. Salarbashi, D.; Jahanbin, K.; Tafaghodi, M.; Fahmideh-Rad, E. Prunus armeniaca gum exudates: An overview on purification, structure, physicochemical properties, and applications. Food Sci. Nutr. 2021, 9, 1240-1255. [CrossRef] [PubMed] 
231. Pabuprapap, W.; Suksamrarn, A. Chemical Constituents of the Genus Trichosanthes (Cucurbitaceae) and Their Biological Activities: A Review. Scienceasia 2021, 47, 1-13. [CrossRef]

232. Xing, X.; Zhi, Y.; Lu, J.; Lei, S.; Huang, L.; Zhu, M.; Fang, K.; Wang, Q.; Wu, J.; Wu, Y.; et al. Traditional Chinese medicine bundle therapy for septic acute gastrointestinal injury: A multicenter randomized controlled trial. Complement. Ther. Med. 2019, 47, 102194. [CrossRef]

233. Wang, W.; Chen, Q.; Yang, X.; Wu, J.; Huang, F. Sini decoction ameliorates interrelated lung injury in septic mice by modulating the composition of gut microbiota. Microb. Pathog. 2020, 140, 103956. [CrossRef] [PubMed]

234. Lai, F.; Zhou, G.; Mai, S.; Qin, X.; Liu, W.; Zhang, Y.; Xie, D.; Weng, Y.; Du, J.; Zheng, Y.; et al. Sini Decoction Improves Adrenal Function and the Short-Term Outcome of Septic Rats through Downregulation of Adrenal Toll-Like Receptor 4 Expression. Evid.-Based Complement. Altern. Med. 2018, 2018, 1-9. [CrossRef] [PubMed]

235. Su, Z.; Yu, P.; Sheng, L.; Ye, J.; Qin, Z. Fangjifuling Ameliorates Lipopolysaccharide-Induced Renal Injury via Inhibition of Inflammatory and Apoptotic Response in Mice. Cell. Physiol. Biochem. 2018, 49, 2124-2137. [CrossRef] [PubMed]

236. Meng, F.; Lai, H.; Luo, Z.; Liu, Y.; Huang, X.; Chen, J.; Liu, B.; Guo, Y.; Cai, Y.; Huang, Q. Effect of Xuefu Zhuyu Decoction Pretreatment on Myocardium in Sepsis Rats. Evid.-Based Complement. Altern. Med. 2018, 2018, 2939307. [CrossRef] [PubMed]

237. Qian, Y.; Qian, F.; Zhang, W.; Zhao, L.; Shen, M.; Ding, C.; Guo, J. Shengiiang Powder ameliorates myocardial injury in septic rats by downregulating the phosphorylation of P38-MAPK. J. Biosci. 2019, 44, 40. [CrossRef]

238. Lu, J.; Yan, J.; Yan, J.; Zhang, L.; Chen, M.; Chen, Q.; Cheng, L.; Li, P. Network pharmacology based research into the effect and mechanism of Xijiao Dihuang decoction against sepsis. Biomed. Pharmacother. 2020, 122, 109777. [CrossRef]

239. Li, S.; Zhang, B. Traditional Chinese medicine network pharmacology: Theory, methodology and application. Chin. J. Nat. Med. 2013, 11, 110-120. [CrossRef] [PubMed]

240. Lan, X.-F.; Olaleye, O.E.; Lu, J.-L.; Yang, W.; Du, F.-F.; Yang, J.-L.; Cheng, C.; Shi, Y.-H.; Wang, F.-Q.; Zeng, X.-S.; et al. Pharmacokinetics-based identification of pseudoaldosterogenic compounds originating from Glycyrrhiza uralensis roots (Gancao) after dosing LianhuaQingwen capsule. Acta Pharmacol. Sin. 2021, 1-18. [CrossRef]

241. Cheng, C.; Du, F.; Yu, K.; Xu, F.; Wang, F.; Li, L.; Olaleye, O.E.; Yang, J.; Chen, F.; Zhong, C.; et al. Pharmacokinetics and Disposition of Circulating Iridoids and Organic Acids in Rats Intravenously Receiving ReDuNing Injection. Drug Metab. Dispos. 2016, 44, 1853-1858. [CrossRef] 